Florida International University FIU Digital Commons

$11-23-1992$

\title{
Stated versus observed performance levels in patients with chronic low back pain
}

\author{
Alma R. Abdel-Moty \\ Florida International University
}

DOI: $10.25148 /$ etd.FI13101503

Follow this and additional works at: https://digitalcommons.fiu.edu/etd

Part of the Occupational Therapy Commons

\section{Recommended Citation}

Abdel-Moty, Alma R., "Stated versus observed performance levels in patients with chronic low back pain" (1992). FIU Electronic Theses and Dissertations. 1079.

https://digitalcommons.fiu.edu/etd/1079 


\title{
ABSTRACT
}

Stated Versus observed Performance Levels

in Patients with Chronic Low Back Pain

by

\author{
Alma R. Abdel-Moty \\ Florida International University, 1992 \\ Miami, Florida \\ Professor Gail Hills Maguire, Major Professor
}

This study examined the relationship between chronic low back pain (CLBP) patients' perceived (stated) levels of function and their measured (observed) performance in squatting and stair climbing activities as compared to healthy volunteers. Twenty patients with CLBP and 20 healthy subjects were asked through an interview to self-assess their ability to comfortably perform stair climbing and squatting as well as other tolerances. The subjects were then asked to perform the activities and their performance levels were recorded. Results of the t-tests and Analysis of Variance (ANOVA) procedures revealed that patients' estimate of squatting and stair climbing abilities as well as their demonstrated levels were significantly lower $(p<0.001)$ than those of the healthy subjects. There was a significant difference between groups in terms of the time required to perform squatting but not stair climbing. Both healthy subjects and patients with CLBP underestimated their physical capabilities. Findings indicate that the use of actual performance measurement combined with self-report of functional abilities is needed when assessing performance levels of both healthy as well as patients with CLBP. 


\section{FLORIDA INTERNATIONAL UNIVERSITY Miami, Florida}

\section{Stated Versus Observed Performance Levels}

in Patients with Chronic Low Back Pain

A thesis submitted in partial satisfaction of the requirements for the degree of Master of Science in Occupational Therapy

by

Alma R. Abdel-Moty 
To Professors Maguire, Kaplan and Johnson:

This thesis, having been approved in respect to form and mechanical execution, is referred to you for judgment upon its substantial merit.

Dean William J! Kepplert College of Health

This thesis of Alma R. Abdel-Moty is approved.

Susăn H. Kaplan -

Paulette Jolknson

\&ail Hills Maguire

Major Professor

Date of Examination: November 23, 1992

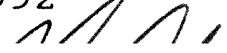

Deand Richárd L. Campbell

Division of Graduate Studies

Florida International University, 1992 
To

Elsayed,

Karima and

Yousef

iii 


\section{ACKNOWLEDGEMENTS}

Appreciation is due to everyone who helped me in the preparation of this study.

My sincere thanks to the members of the thesis committee who made an idea become reality. To susan H. Kaplan, I am grateful for her comments, input and encouragements in the preparation of this document. To Paulette Johnson who helped me tremendously with the statistical analysis I am also grateful. Special thanks to the chairperson of the committee, Gail Hills Maguire for her support, guidance, willingness, assistance, editorship and critique given throughout this thesis. Her organizational abilities and attention to details kept me on track from beginning to end of the study. You are really a mentor!

I would also like to thank Dr. \& Mrs. Rosomoff for letting me use the patients of the institution which they direct as part of the project.

My appreciation goes to Haradya Cantillo who helped me with data collection.

My gratitude also to the patients and persons who volunteered as controls for my study.

My sincere appreciation to the occupational Therapy staff at the University of Miami Comprehensive Pain Center for their support and frequent reassurance. My thanks also go to Ismael Miranda, OT supervisor, for his understanding and encouragement throughout this project.

special thanks to my parents who always supported me in my projects and who set a good example; and encouraged me to continue my graduate studies. To papa, here is my M.S.

And lastly I would like to express my deepest gratitude to my husband, Elsayed who always stood beside me in the course of this project. Thank you for your patience, understanding, for the time dedicated to me and my project as well as your unconditional love. Thanks for the guidance, your invaluable expertise with the computer and your constructive criticism. You are a true researcher! 


\section{Table of contents}

List of Tables

List of Figures

Chapter I

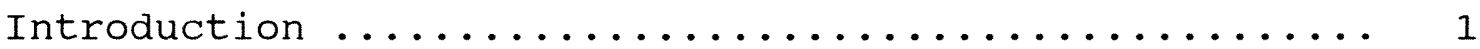

Application of the Model of Human Occupation...... 1

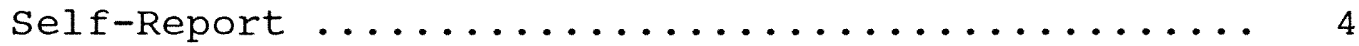

Self-Report versus Professional Evaluation .. 5

Self-Report versus Interview $\ldots \ldots \ldots \ldots \ldots \ldots 7$

Self-Report versus Performance $\ldots \ldots \ldots \ldots \ldots$. 8

Purpose of the study $\ldots \ldots \ldots \ldots \ldots \ldots \ldots \ldots \ldots$

Statement of the Problem ................. 9

Objectives, Questions, Hypothesis ............ 10

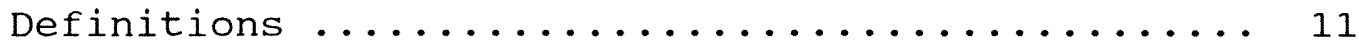

Significance of the study $\ldots \ldots \ldots \ldots \ldots \ldots \ldots \ldots$

Assumptions........................... 14

Chapter II

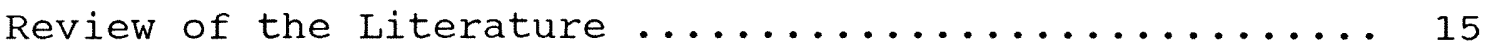

The Problem of Low Back Pain (LBP) .......... 15

Performance Evaluation in LBP Patients ........ 17

Self-Reported Measures................... 19

Self-Report versus Actual Performance ........ 22 
Self Report of Pain Level (VAS) $\ldots \ldots \ldots \ldots \ldots \ldots 23$

The Model of Human Occupation and Low Back Pain... 24

Performance................... 24

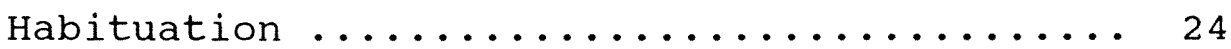

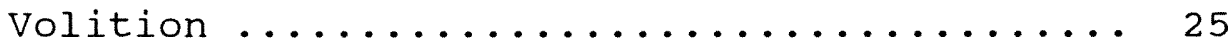

Chapter III

Research Procedures / Methodology .............. 28

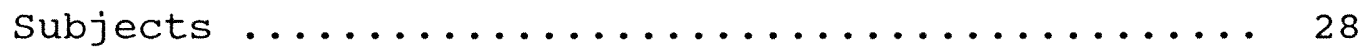

Subjects Exclusion Criteria .......... 28

Experimental Design .................. 29

Experimental Procedures ............... 30

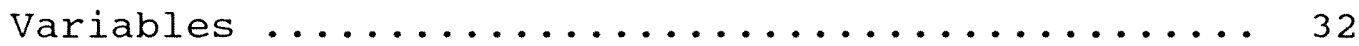

Limitations of the study $\ldots \ldots \ldots \ldots \ldots \ldots \ldots \ldots \ldots \ldots$

Chapter IV

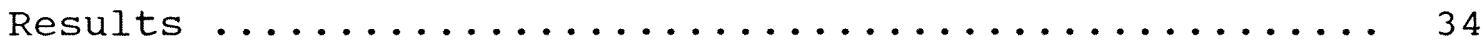

Demographics ...................... 34

Analysis of the Response Variables .......... 36

Analysis of Squatting \& Stair Climbing Variables.. 37

Results of the Analysis of Variance ...... 39

Analysis of Pain Variables .............. 40 
Chapter V

Discussion and Implications ................. 42

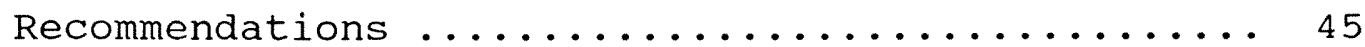

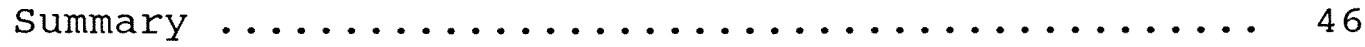

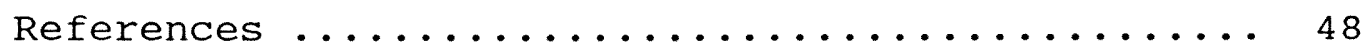

Appendices ........................... 56

Appendix A Standard consent Form

Appendix B Data Form \& Intake Interview

Appendix C Performance Data

Appendix D Visual Analog Scale

Appendix E Tables

Appendix F Figures 


\section{List of Tables}

1 Demographic Variables of Both Study Groups

2 Chi-Square Comparison Between Groups on Categorical Demographic Variables

3 Means and Standard Deviations of Quantitative Demographic Variables of Study Groups

4 Descriptive Information of the Patient Study Group

5 Means and Standard Deviations of stated Tolerances Obtained During Initial Interview of the Study Groups

6 Means and Standard Deviations of the Squatting and Stair Climbing Response Variables of the Study Groups

7 Summary of the Analysis of Variance (ANOVA) Results for the squatting Variable

8 Summary of the Analysis of Variance (ANOVA) Results for the Stair Climbing Variable

9 Mean Values of Squatting and Stair Climbing Tolerances for Males and Females in Both Study Groups

10 Means and Standard Deviations of Pain Variables for the Patient study Group 


\section{List of Figures}

1 Stated and Observed Squatting Tolerances for the Study Groups

2 Stated and Observed Stair climbing Tolerances for the study groups

3 (Observed - stated) squatting and stair climbing for the study Groups

4 Time to Perform Squatting and stair climbing for the study Groups

5 Stated and observed Squatting Tolerances for the study Groups by Gender

6 Stated and Observed stair climbing for the study Groups by Gender 


\section{Chapter I}

\section{Introduction}

Low back pain (LBP) is a well known disability that is experienced by approximately $80 \%$ of the people in industrialized countries during their life time (Locke, 1983). LBP is often associated with functional disability, economical and social consequences, and enormous burdensome effects upon industry, health care systems, and society. Estimates suggest that 14 to 60 billion dollars are spent for the treatment of LBP in the United states every year (Schaepe, 1982; Bonica, 1980). In the management of LBP, pain reduction and functional restoration are desired goals. These, in turn, can be reflected in increased productivity and reduction of rising disability costs. The evaluation of the effectiveness of LBP rehabilitation is difficult because the interaction of many factors is complex and patients' perception of factors such as functional ability and pain is subjective.

Application of the Model of Human Occupation

Current literature lacks documentation regarding occupational therapy theories specifically related to patients suffering from LBP. However, the Model of Human Occupation (MOHO) encompasses the issues of this population. According to this model, the individual is viewed as an open 
system with three hierarchical subsystems (Kielhofner, 1985, 1992). These subsystems interact with the environment to produce actions or occupational behavior. All subsystems are affected in the back patient.

The performance subsystem, which incorporates the skills necessary to produce a task, will be affected because people with chronic low back pain experience disturbance to musculoskeletal constituents of skills. Patients may be unable to perform tasks like lower extremity dressing, getting in or out of the back seat of a two door car, shaving their legs and cutting their toenails. Activities like squatting and stair climbing may be decreased due to increased pain.

The habituation subsystem, which encompasses the roles and habits, will also be affected. A pain patient usually experiences a decrease in roles and habits. Frequently the pain patient encounters new roles which are less voluntary and less pleasant than before. The patient role may replace the worker role. Certain behaviors may be eliminated from the person's routine or the person may have to delegate some tasks to family members (Kielhofner, 1985).

Habits will also be disturbed due to the lack of skills and inactivity imposed by the pain.

occupational therapy is concerned with maintaining the highest level of function in the LBP patient with the least 
amount of pain. Typical OT goals are to increase endurance and to increase tolerance for activities of daily living (ADL) such as sitting, standing and walking.

The volition subsystem addresses values, personal causation, and interests which influence motivation in order to determine occupational behavior. Pain patients usually view themselves as incompetent and experience a disruption in the volitional subsystem at the time of injury. This disruption may extend for a long period of time.

Individuals' beliefs in skill are affected when old skills are lost or new requirements for performance may include modifications such as the use of corsets, cushions, or back braces. Many pain patients link pain and impairment, believing that they are unable to live normal lives as long as they experience pain. These patients use pain relief as a prerequisite to resuming a normal, active lifestyle and often look for the "magic cure" that will eliminate their pain. When the "magic cure" eludes them, they remain impaired and may become frustrated, angry and disenchanted with the medical system.

In occupational therapy (OT), activities are graded from simple to difficult so that low back pain (LBP) patients build up self-esteem and are able to function in their environments. Patients are informed that total pain relief may not be attained. Emphasis of treatment is on an 
increase in function and not toward pain elimination. Given the fact that culture and family have an effect on treatment outcome, therapists must choose treatment activities thoughtfully.

Due to pain, persons may experience incongruence between what they value or believe they should do and what they can actually do. For example, pain patients may be able to sit for only a limited period of time which limits participation in valuable occupations.

Interests are also disrupted in pain patients' lives. Due to pain, they can often no longer perform those activities that they enjoy. The occupational therapist addresses avocational activities as part of the treatment so that patients can enjoy their usual interests again.

The occupational therapist conducts evaluation of LBP patients in the areas of performance, habituation, and volition. Methods of evaluating LBP patients include selfreport of function and symptoms, as well as actual performance evaluation. Treatment is based on the evaluation results.

\section{Self-Report}

In many cases, the health care professional may rely upon patients' self-report of pain location and level, medication intake, and deficiencies in activities of daily 
living in addition to clinical assessments. Patients' selfreports of their ability to perform movements have been referred to as perceived self-efficacy (Council, Ahren, Follick \& Kline, 1988). Bandura (1977) defined self-efficacy as "the expectancy of successful performance in a problem situation" (p. 191). When considered in relation to pain, self-efficacy expectancies have typically been defined as a person's perceived ability to cope with pain (Council et al., 1988). Self-report scales gather information about an individual's perception of their illness behaviors, emotional states, functional limitations, and attitudes about pain and illness (Ogden-Niemeyer \& Jacobs, 1989).

In general, patients' expectancies of physical impairment and pain have been reported to bear a substantial relationship to actual performance (Council et al., 1988). A closely related concept to perceived self-efficacy is outcome expectancies defined by Jensen, Turner \& Romano (1991) as "a belief about the consequences of performing a behavior" (p. 263). According to these concepts it can be concluded that patients will demonstrate low levels of performance if they perceive themselves impaired.

Self-Report versus Professional Evaluation. Studies of self-assessment instruments have included comparisons of patients' self-assessments of their activity level and 
therapists' written and observational assessments. Most available research demonstrates lower perceived performance levels obtained through self-report than the same levels recorded by professional observations. Kremer, Block \& Gaylor (1981) assessed the accuracy of self-report of physical activity, social behavior, and pain intensity in four in-patients admitted to a chronic pain unit. Staff observations of patient activity were made concurrently with patient self recordings of the above variables. The results can only be suggestive due to the small sample size but indicated that three of the four patients significantly underreported their level of activity and social behavior when compared to staff observations. However, it is unclear from the report whether the patients were aware of the staff's recording of their behavior during sampling periods. The authors concluded that treatment outcomes should be evaluated on the basis of objective measures rather than relying on self-report.

In a study by McGinnis, Seward, DeJong \& Osberg (1986) a self-report questionnaire was completed by the patient or family member both during the rehabilitation stay and after discharge. After the reports were completed, assessments by professionals were obtained. A comparison of the patient assessments with the professional assessments indicated significant differences between patients' and therapists' 
ratings, with patients reporting lower ratings. In a study by sheikh et al. (1979), stroke patients claimed significantly more difficulty performing tasks at home than was found when the hospital staff observed these activities. MCGinnis et al. (1986) offered the following reasons to explain the finding that therapists consistently rate patients higher than the patients rate themselves: 1) patients are anxious; 2) patients assume the sick role; 3) therapists are trying to demonstrate effectiveness of the rehabilitation program; 4) patients and therapists have different interpretations of functional ability; and 5) patients and therapists use different comparison rules in evaluating functional ability.

Self-Report versus Interview. Discrepancies have been reported between what patients report as being their activity level in a self-administered instrument as compared to what they report when interviewed (Spiegel, Hirshfield and Spiegel, 1985; McGinnis et al., 1986). Spiegel et al. (1985) compared assessments of self-care activities obtained from patients' self-administered questionnaires and occupational therapists' interviews. Patients reported requiring more assistance with self-care activities in self-administered questionnaires than they did in occupational therapy interviews. Patients appeared more willing to admit difficulties with self-care activities in 
a self-administered questionnaire than in a personal interview.

Self-Report versus Performance. The difference between what patients report as being their functional level and what they can actually do has also been studied (council et al., 1988; Sanders, 1980). Sanders (1980) used an automated electromechanical monitor for the objective assessment of 'uptime' for chronic pain patients. Uptime was defined as either the amount of time spent standing, walking, or out of bed. Results were compared to patients' self-reports of the same activity. The author reported that chronic pain patients showed significant underreporting of uptime relative to that measured by the automated monitor. In contrast, Follick, Smith \& Ahern (1985) did not find such a difference between the same measure of uptime/downtime and self-report of the activity. They used a similar automated electromechanical monitor and results were compared to: 1) patients self-report on a daily activity diary; and 2) espousal observations of the same activities. The authors found a significantly positive correlation between patients' reports of down-time and the down-time measured by the monitor. 


\section{Purpose of the study}

The purpose of this study was to establish the relationship between chronic LBP patients' stated levels of function and their measured performance in a select number of activities.

Statement of the Problem

Patients' self-reports of level of function in performing activities of daily living have been used as integral components of clinical evaluation. This is based on the belief that patients' performances will match their perceptions of their ability. People's self-statements and appraisal of events, feelings, and behaviors are central to the management of chronic pain (Kores, Murphy, Rosenthal, Elias \& North, 1990). Performance of actions necessary for meeting treatment goals may be affected by people's judgment of their skills (Bandura, 1977). Perceived self-efficacy for coping with pain may also determine the ways in which people deal with situations associated with pain. Self-efficacy expectancies have also been found to correlate significantly with tolerance for physical activities (Dolce, Crocker \& Dolys, 1986). Self-efficacy expectancies reflect behavioral intentions (Kirsch, 1986) and may ultimately determine performance (Council et al., 1988). 
Evaluation of research in the area of self-reporting by low back pain patients is limited by the lack of baseline information regarding how accurately healthy subjects can estimate their abilities to perform certain tasks identified as problematic for low back pain patients. Additionally, while some studies report inconsistencies between selfreport and observations, others tend to disagree.

The literature signals that self- reports are a useful tool. However, it remains important to identify the difference between patients' subjective reports of various activity levels and their actual performance levels. Identification of the difference between patients' perception of various activity levels and their actual performance levels can be valuable to help the patient establish realistic expectations; to use the patient as a collaborator when setting personally significant treatment goals; and to understand the effects of chronic pain on patients' perception of their abilities and limitations.

\section{Objective, Question, Hypothesis}

The objective of this investigation was to study the relationship between patients' "stated" (or perceived) levels of function and their "observed" (or actual) levels of performance. 
The following research question was addressed:

Is there a difference between what patients with chronic LBP perceive as their ability to squat and climb stairs and what they can actually do as compared to control subjects?

\section{Definitions}

The operational definitions for this study were adopted from the following sources: Gamboa, Holland and Tierney (1988); Funk \& Wagnalls (1984) and Webster (1984).

Squatting: Crouching close to the ground with the knees bent and the weight on the balls of the feet to bring legs near body.

Stair Climbing: Ascending and descending flights of stairs by using the feet and while holding on to a railing with one hand.

\section{Significance of the study}

Available research reports poor correlation between what patients report as their activity level, on one hand, and what they can actually do based on observations, monitoring, or espousal rating; with most self-reports being the lower score. However, self-reports are seen as valuable because they are easy to obtain, convenient, less costly, and require minimal professional time. One factor limiting the interpretation of pain patients' self-reports of 
performance is the lack of information regarding what healthy subjects estimate as their ability to perform certain tasks compared to their actual performance. Therefore, this study explored the relationship between self-report and performance in patients with low back pain as compared to healthy subjects.

Findings from this study proved useful in explaining the reported inaccuracy regarding chronic low back pain patients' statements of their functional levels (e.g. Schmidt, 1985). Understanding this perception enhances therapists' awareness of how much of the problem may be due to functional limitations and how much is affected by how patients perceive themselves as being limited. Understanding patients' perceptions of their functional levels may also be useful in interpreting patients' expectations about treatment. Patients who tend to overestimate their skills may place undue hardship on themselves if they report a desired goal of treatment which is higher than what is realistic. Since findings suggest that patients underestimate their abilities, this indicates the need for patient education program which emphasize what the patients are capable of doing. Therefore, identifying the difference between patients' perceptions of their activity level and their actual performance level can be helpful to the treatment planning process. 
In the treatment of chronic low back pain, Occupational Therapy addresses the issues of limitations in performing activities of daily living and associated tolerances. The occupational therapist addresses many aspects of treatment related to self-care and prevention of further or new injury. In order for the treatment to be effective, it is necessary to corroborate whether or not the patient selfreported activity level is accurate.

For the purpose of this study, squatting and stair climbing were chosen because they are important components in many daily activities and tend to be limited in low back patients. Squatting is an activity which is incorporated in many functional tasks. It requires lower extremity strength, as well as coordination and balance. Squatting ability is needed in activities of daily living such as: getting objects from the bottom cabinet in the kitchen and picking objects (pencils, cloth, grocery bags) from the floor. Proper squatting enables the patient to lift various objects from the floor or low levels correctly without increased pain or discomfort.

Stair climbing places demands on the hips and lower extremity musculature and can exacerbate pain if performed incorrectly. Ascending and descending stairs requires the ability to alternately shift body weight from one leg to the other. Strength, endurance, and balance are essential in 
order to perform this task. Climbing stairs helps the patient improve strength, endurance, and tolerance to levels necessary for independence and safety. When the patient climbs stairs, the occupational therapist observes balance, posture, and pacing while monitoring for any cardiovascular and respiratory signs. Stair climbing ability is a requisite for multiple story housing without elevators, and in emergency fire evacuations from most buildings.

\section{Assumptions}

In carrying out this study, the following assumptions were made:

1. Subjects were not biased by previous knowledge of how much they can perform.

2. Subjects reported, to the best of their knowledge, the level to which they could perform the activities.

3. Participants' observed performances were not biased by their previous self-reported perceptions of their abilities. 4. The measures selected for analysis, squatting and stair climbing, are part of subjects' daily activities. 
Review of the Literature

This review highlights available scientific material in the literature pertaining to the purpose and objectives of this study. This entails information related to the magnitude of the problems of chronic low back pain (LBP), performance evaluation in LBP patients with emphasis on occupational Therapy evaluations, self-reported measures, and literature relating patients' perceptions and actual measurement of abilities, especially with reference to activities of daily living.

\section{The Problem of Low Back Pain}

Low back pain is a well known disability that is experienced by a large segment of the society. Backaches can strike almost anyone, the young and the old, males and females, people of all classes and professions. Although the exact incidence of LBP is unknown, it is obviously high. It has been estimated that 70 to $80 \%$ of the people in industrialized countries will develop some form of back pain during their life time (Horal, 1969; Hult, 1954; Nachemson, 1971; Leavitt, Johnson \& Bayer, 1971; Eagle, 1979; Hasue and Fujimara, 1979; Locke, 1983). Annual estimates of the new cases of LBP have ranged from $10 \%$ to $15 \%$ of the United States population (Steinberg, 1982). Impairments of the back 
are the most frequent cause of activity limitation in persons under the age of 45 and are the third most common cause of disability after heart and arthritic conditions in people 45 years old and over. LBP is often associated with functional disability, economical and social consequences, and enormous burdensome effects upon industry, health care systems, and society. Estimates range from 14 to 60 billion dollars spent annually for the treatment of LBP in the United States (Schaepe, 1982).

A myriad of medical treatment approaches have been advocated by different care providers in response to the magnitude of the LBP problem (Bonica, 1980). A successful program for the rehabilitation and management of LBP should integrate the different medical treatment disciplines in order to accomplish such goals as: restoration of function; pain reduction; and consequently, increased productivity and reduced disability costs (Rosomoff, 1985).

The effectiveness of LBP rehabilitation requires evaluation methodologies that are reliable, objective and comprehensive (Khalil et al., 1987). Objective evaluation of patients' functional abilities is a useful tool to assess the loss of function due to injury or disability, and to direct rehabilitation efforts in order to: 1) achieve total restoration of the functional loss, 2) monitor patients' progress during rehabilitation, 3) measure rehabilitation 
outcomes and efficacy, and 4) examine the patients' abilities to re-enter a more productive lifestyle (Granger and Greer, 1976). Accurate assessment of physical function can also be a useful tool in the process of matching patients' abilities and their job demands in order to deter re-injury (Dolce et al., 1986).

\section{Performance Evaluation in LBP Patients}

Forms of evaluating LBP sufferers have traditionally included medical and laboratory tests, self-assessments and evaluations by physicians, physical therapists, occupational therapists, psychologists, and vocational specialists. For the purpose of this study patient self-assessment and performance will be discussed. The other forms of evaluation can be found elsewhere (Roland and Morris, 1983; Lankhorst, Stadt \& Vogelear, 1982).

In recent years, investigators have developed elaborate functional classification systems designed to evaluate the effects of therapy or rehabilitation on patient outcomes (Jette, 1980). Most of these instruments use a 4 or 5 point multiple choice scale that orders respondents' degrees of dependence in performing several global activities of daily living (Granger \& Greer, 1976; Katz, Downs, Cash \& Grotz, 1970). The accuracy and reliability of most instruments have been established by test-retest as well as patients' reports 
versus ratings by other individuals (Follick et al., 1985; Kremer, 1981). Most studies have reported discrepancies between what patients report as their activity level, on one hand, and what they can actually do based on observations, monitoring, or espousal rating with most self-reports being the lower score.

The literature has shown that there are many shortcomings associated with self-reported measures used to evaluate activity level of pain patients. In particular, self-report measures allow a number of variables to enter into the evaluation process. In low back pain patients, some of these variables are:

1. social desirability needs on the part of some patients ;

2. patient attitude towards treating physician or rehabilitation setting;

3. perceived secondary gains on the part of both the patient and sometimes the physician (Khalil et al., 1987).

These variables are entered into the evaluation process and bring about the question of reliability and validity of self-report measures. Reliability is an important characteristic of a measuring tool. For most purposes, instruments can be considered reliable when reliability estimates fall between 0.8 and 1.00 , as moderately reliable when the estimates fall between 0.6 and 0.79 , and of 
questionable reliability when the estimates fall below 0.6 (Richman, Makrides \& Prince, 1980).

\section{Self-Reported Measures}

Patients' self-reports of level of function in performing activities of daily living has been used as an integral component of clinical evaluation. Self-reports are used to complement the therapist's interview, thus enhancing the therapist's awareness of perceived problems with self care (Spiegel et al., 1985). Self-report measures are easier to obtain than observations and measurements; may be convenient and less costly; require minimal professional time (McGinnis et al., 1986); address sensitive issues that may be difficult to bring up in a face-to-face interview; and may elicit responses regarding behaviors, knowledge, and attitudes which are unmeasurable using devices (Rintala and Willems, 1991). Self-report questionnaires can also provide information about everyday activities that may be difficult to measure in a rehabilitation setting or under observation. They have been shown to be feasible in quantifying levels of function (Jette, 1980). Self-report instruments are, however, of limited usefulness for patients with cognitive impairment or mental handicap (Barnes and Benjamin, 1987). The health care professional can gather useful information by screening for obvious high scores, looking at how the individual answers certain test items, comparing the scores 
of similar scales to look for consistency, and by noting the tendency to make exaggerated responses not in keeping with observed distress or performance (Ogden-Niemeyer and Jacobs, 1989).

Self-report instruments may also be used to design treatment approaches in goal-oriented rehabilitation programs. In this case, the patient's self-report of his/her activities of daily living requirements is used to determine the goal of treatment. Inaccuracy in the self-report in this case may result in patients either underachieving or making unrealistic goals. Self-report instruments have also been used to measure changes upon treatment but have not demonstrated an ability to detect subtle changes in function (Jette, 1980). Patients' self-reports have also been suggested as a tool in the evaluation of a rehabilitation program's efficiency and services (McGinnis et al., 1986).

In recent years, investigators have developed elaborate functional classification systems design to evaluate the effects of therapy or rehabilitation (Jette, 1980). Most of these instruments use a 4 or 5 point multiple choice scale that orders respondents' degree of dependence in performing several global activities of daily living (Granger \& Greer, 1976; Katz et al., 1970).

The reliability of most instruments have been established in relation to test-retest as well as with 
respect to pain patients' report of sickness impact on ADLs versus, e.g., spousal ratings of the same activities (Follick et al., 1985).

Additionally, the accuracy and validity of selfassessment instruments have been subject to many investigations, especially when comparing patients selfassessment of their activity level and therapist's paper-and-pencil assessment (e.g. Spiegel et al., 1985; McGinnis et al., 1986). In addition, discrepancies have been found between what patients report as being their activity level in a self-administered instrument as compared to what they report when interviewed. For example, spiegel and others (1985) compared assessments of self care activities obtained from patient self-administered questionnaires and occupational therapists' interviews. Patients reported requiring more assistance with self-care activity than they did in an occupational therapy interview. In a study by MCGinnis et al. (1986) a self-report questionnaire was completed by the patient or family member both during the rehabilitation stay and after discharge. After the reports were completed, health professional assessment were obtained. A comparison of the patient self-reports to those made by the health professionals indicated significant differences between patients' and therapists' ratings, with patients reporting lower ratings. These findings render 
patients' self-reports to be of questionable validity.

\section{Self-Report versus Actual Performance}

In order to evaluate changes in function, chronic pain patients are frequently asked to keep daily logs of their "up-time". "Up-time" is defined as the amount of time spent standing or walking or the amount of time spent out of bed (Sanders, 1983). For some patients, however, the reliability of diary data may be poor (White \& strong, 1992). Subjects may report inconsistently or may be unduly influenced by emotional factors (Sanders, 1983). Due to this problem several researchers have developed automated devices that automatically record patients activity levels. Cairns, Thomas, Mooney and Pace (1976) developed a stationary electronic device that could be attached to chairs and beds to automatically record up-time. Since chronic pain patients have access to many places to sit or lie down apart from those with monitoring devices, the true validity of these devices as an accurate measure of up-time has been questioned (Sanders, 1980).

A comparison of self-report and the use of a portable automated timing device worn for continuous monitoring of up-time was studied by white and strong in 1992. They concluded that patients recorded significantly lower levels of up-time with self monitoring than with the electronic 
device. This discrepancy corroborates the findings of other researchers (Kremer et al., 1981; Sanders, 1980).

The difference between what patients report as being their functional level and what they can actually do has been studied in a very limited number of studies. Follick et al. (1985) studied the correlation between patient selfreport of uptime and downtime (time in bed) and objective assessment of the same variables. The authors reported positive and highly significant correlation between both variables.

Self Report of Pain Level (Visual Analog Scale)

The visual analog scale (VAS) (Chapman, Casey \& Dubner, 1985; Price, McGrath, Rafii \& Buckingham, 1983) is a rating scale that patients use to indicate their pain level. It consists of a $10 \mathrm{~cm}$ line with two extremes of pain. The extreme closer to zero reads "no pain" and the one closer to 10 reads "pain as bad as it could be". Patients are asked to make a mark on the line which best represents their perceived level of pain. It is scored by measuring the distance from the "no pain" to the mark made by the patient. Chapman et al. (1985) have placed the VAS at a disadvantage since: 1) the VAS assumes pain to be an unidimensional experience which varies only in intensity, and 2) the VAS is subject to response biases. The VAS has been shown to be 
internally consistent both in experimentally induced pain and patients' chronic pain, thereby demonstrating validity. The VAS has been shown to be more sensitive than verbal rating scales (Jensen, Karoly \& Braver, 1986).

The Model of Human Occupation and Low Back Pain

The MOHO was developed by Kielhofner \& Burke (1980) and is an adaptation of the model of human behavior developed by Mary Reilly in 1962. The Model of Human Occupation views the individual as an open system; with groups of subsystems in dynamic interaction with the environment. The environment includes external objects, people and events that influence action. The three subsystems (Performance, Habituation, and Volition) are arranged in a hierarchy and interact together to produce actions or occupational behavior (Kielhofner, 1992) •

Performance. The performance subsystem occupies the lowest level and consists of basic capacities called skills. It is ruled by the habituation and volition subsystems. skilled action requires both physiological (neurological and kinesiological) and symbolic functions (Kielhofner and Burke, 1980).

Habituation. The habituation subsystem constitutes the middle level in the human occupation model. It organizes behaviors or performance into patterns or routines. Habits 
and roles are automatic routines of behavior that function to maintain behavior so that it occurs consistently and predictably (Kielhofner \& Burke, 1980).

The literature demonstrates that LBP interrupts roles, especially the worker role. Patients with back pain are usually unable to engage in gainful employment (shutty, De Good \& Schwartz, 1986). They spend a significant proportion of their waking hours lying down (Turk \& Holzman, 1988) and experience a restriction in their social and recreational activities (Rosenstiel \& Keefe, 1983).

According to Rosenberg (1980), the individual who has made the transition from healthy person to patient may find that both the physician and non-physician expect him to act a certain way. He should want to get better, and do what he is told by the doctor. In return he is exempt from obligations such as his usual work and family duties. These expectations apply to all hospital patients which suggest that hospital staff may give little consideration to a patient's needs related to wishes, ethnicity or financial status (Robinson, 1987).

Volition. The volition subsystem occupies the highest level and governs the lower subsystems. It includes values, personal causation, and interests. Values indicate what is desirable and meaningful in life and serve as central 
principles for mediating the way which occupational goals are satisfied (Kielhofner, 1985).

Patients develop an understanding of illnesses through personal beliefs associated with their afflictions (Williams \& Thorn, 1988). These beliefs develop through the assimilation of new information with pre-existing meanings and action patterns held by the patient (Leventhal, Zimmerman \& Gutmann, 1984). Given the unique histories of individual patients, it is likely that personal beliefs vary in some degree from representations offered by health professionals (Williams \& Thorn, 1988). Personal beliefs about illness can greatly diminish compliance if discordant with the treatment offered (Becker et al., 1977). Pain beliefs may be defined as a subset of a patient's belief system which represents a personal understanding of the pain experience (Schwartz, De Good \& Shutty 1985). Patients' beliefs about chronic pain affect behavior independently of patients' stated knowledge about chronic pain treatment (Shutty et al., 1986).

The profile of the back patient is usually labeled as the low back loser in steele-Rosomoff's study (cited in Rosomoff, 1985). The back pain patient is one with a self-defeating background.

Culture plays an important role in the rehabilitation of the pain patient. Understanding the differences in 
cultural perceptions of pain may guide the therapist in choice and duration of activities that may elicit pain (Robinson, 1987). In 1980, Rosenberg studied the relationship of culture to pain. The study indicated that Italians are sensitive to the immediate pain experience and are happy when relief is obtained. Jewish people viewed pain as indicative that their bodies were falling apart, and so even in the face of relief might continue to complain. Irish people, on the other hand, accepted pain as a fact of life and might deny that anything was wrong.

Patients' ethnic origin can surely affect their view of a regimen assigned to them if it violates their cultural values or their response to it is not fully understood by the therapist (Robinson, 1987). 


\section{Research Procedures/Methodology}

Subjects

A total of 40 subjects, in two groups participated in this study. The experimental group consisted of 20 patients (10 males and 10 females) with chronic low back pain (pain of more than 3 months in duration since onset) as the primary diagnosis. Subjects for the patient group were qualified consecutive admissions to the University of Miami Comprehensive Pain and Rehabilitation center (CPRC) at south Shore Hospital and Medical Center, Miami Beach during a two month period. The control group consisted of 20 healthy volunteers ( 10 males and 10 females). Subjects for the control group were volunteers from the non-clinical CPRC staff such as clerical and support services employees with no reported incidence of low back pain.

Subjects Exclusion criteria. In general, subjects with the following conditions were excluded from the study:

1. Knee and/or hip replacements.

2. Inability to ambulate independently.

3. Use of ambulation devices (e.g. cane or walker).

4. Cardiac precautions.

5. Cognitive deficits.

6. Psychiatric deficits.

7. Non-English speaking. 


\section{Experimental Design}

This experiment had one grouping factor ( Patients and Healthy). To compare the two groups, data was collected on various demographic characteristics such as: ethnicity, educational level and employment. Data was analyzed using chi-square tests for categorical variables, t-tests and Analysis of Variance for numerical variables.

The dependent variables were: the stated stair climbing tolerance, observed stair climbing tolerance, stated squatting tolerance and observed squatting tolerance. Stated tolerances were obtained via therapist interview of the subjects. Efforts were made to control the following variables: time of the testing (8-10 AM for stair climbing and 1-2 PM for squatting activities) and stopping or end point (increased pain beyond tolerance, or 30 flights and 30 squats)

Two sample t-tests were performed between patients and controls to compare the differences between stated and observed tolerances for each activity. In addition, to see if either group under or over estimated performance, individual group t-tests were conducted on the mean of differences for each activity.

For patients only, descriptive statistics and t-tests on several pain variables including self-report of pain before and after each activity are presented. 
All data analysis was carried out using sPs for personal computers (SPSS/PC) (SPSS/PC+ Guide, 1991). Results were considered statistically significant at the 0.05 level.

\section{Experimental Procedures}

The experimental procedure was part of each patient's regular occupational Therapy initial evaluation protocol currently in place at the comprehensive Pain and Rehabilitation center. There was no risk to the patient. Therefore, no signed consent form was required.

For the purpose of this study, the following specific procedures were followed and apply to both groups, patients and healthy subjects:

1. During the first session, an initial interview was conducted in order to: (a) document medical history, biographic information (data collection form is included in Appendix B); and (b) to obtain self-reported pain level for the patient group only, through the use of the Visual Analog Scale (VAS, Appendix D). Patients were requested to rate their pain on a visual analog scale under the following conditions:

"rate average pain over the last 24 hours";

"what level of pain do you consider intolerable?";

"for what level of pain would you consider taking medications?" ; 
"what level of pain do you consider disabling?"; and "rate the change in pain over the last month".

Subjects in both groups were oriented as to procedures and expectations. Subjects were, then, asked to self-assess their ability to comfortably perform stair climbing and squatting as well as other tolerances through interview questions.

2. On the following day, subjects performed stair climbing (in the A.M. period) and squatting (in the P.M. period). Achievement (number of repetitions, time to complete each task, self-report of pain level and location) were recorded on the data sheet (Appendix $C$ ).

3. Squatting was performed with bilateral cylindrical grasp on a fixed horizontal rail 36 inches from the floor, with feet 15" apart, and trunk straight. The required body posture for squatting was demonstrated to each subject. Activity was self-paced by the subject. However, the time to perform the activity was recorded.

4. For stair climbing activity, subjects were asked to climb and descend one flight of stairs (10 steps) to tolerance or a maximum of 30 flights. Reasons for stopping the activity was documented.

5. For the patients' group only, self-report of pain level was recorded before and after each task. 


\section{Variables}

a. Dependent.

1. Stated stair climbing tolerance.

2. Observed stair climbing tolerance.

3. Stated squatting tolerance.

4. Observed squatting tolerance.

b. Independent.

1. Groups (patients and healthy subjects).

c. Controlled.

1. Time of the day: 8-10 A.M. to test stair climbing and 1-2 P.M. to test squatting activity.

2. End-Point:

a. Increased pain beyond tolerance;

b. 30 flights of stairs and 30 squats.

c. Major deviation from established posture.

\section{Limitations of the study}

1. Only patients with chronic low back pain were included in the study. None of the patients were in the acute phase of injury.

2. A large percentage of the patients were diagnosed as myofascial syndrome; a soft tissue injury.

3. The sample included in this study was selective in terms of the exclusion criteria. Patients were excluded from 
the study under any of the following conditions: knee and/or hip replacements, inability to ambulate independently, use of ambulation devices such as a cane or a walker, cardiac precautions, cognitive deficits, psychiatric deficits, nonEnglish speaking.

4. All patients were on at least one type of medication. The non-narcotic pain medication was the most used (100\%) followed by sleep medications (85\%), narcotics (50\%) and antidepressants (35\%). 


\section{Results}

In the following sections, the results obtained from analyzing the various demographic data as well as the response variables are presented for both groups studied as indicated. Data was analyzed through the use of descriptive statistics, chi-square test, t-test statistics, and Analysis of Variance (ANOVA) procedures. Tables and figures cited in this chapter are included in Appendix $E$ and Appendix $F$ respectively.

\section{Demographics}

The results of analyzing the various demographic variables are presented in Table 1 for both study groups. There was an equal number of males and females in each group. In this sample, analysis of the variable religion showed that $40 \%$ of the patients and $60 \%$ of the healthy were Catholics. Also, it was found that $60 \%$ of patients and $55 \%$ of the healthy subjects were married. Thirty five percent of the patient group had a high school diploma and so did $40 \%$ of the healthy group. The results of the chi-square test of the comparison between the two groups in this type of categorical data are presented in Table 2 . It can be seen that there was an equal number of males and females in each 
group. The major composition of the patient group was white-non-hispanic (60\%), whereas $55 \%$ of the control group were white-hispanics. This discrepancy was not statistically significant $(p<0.067)$. There were no differences between groups when compared on the basis of the religion, marital status, or education variables. Groups differed in the employment status of their subjects $(p<$ 0.005 ) with only $50 \%$ of the patient group being employed full-time prior to admission for treatment as compared to $95 \%$ of the healthy subjects.

The means and standard deviations of the quantitative variables for both groups are presented in Table 3. Table 3 also presents the results of the t-test on the same variables comparing both groups. The average ages were 42.7 and 41.8 for the patient and the healthy subjects respectively. As can be seen, there was no statistically significant difference between groups when compared on the basis of age, height, weight, obesity index (Calculated as: body weight in kilograms + height in centimeters - 100; Blacklow, 1983), years in school, or the level of work activity (job categories) .

Results of analyzing the additional descriptive information of the patient group are presented in Table 4 . As can be seen from this table, the largest percentage of the patients (45\%) reported having an onset of pain from 
1 to 5 years ago. When asked whether they are planning to return to work or not, $70 \%$ indicated a desire to return to work following treatment and $25 \%$ were not sure about their return to work status (Table 1 ). In this sample of chronic low back pain patients, $70 \%$ of the patients were classified as workers' compensation, $20 \%$ had private insurance, and $10 \%$ were within the Medicare system.

sixty percent of the patients were treated as inpatients and $40 \%$ were treated on an outpatient basis. When compared on the basis of the admission medical diagnosis, $80 \%$ of the patients received a diagnosis of lumbar myofascial syndrome and the remaining $20 \%$ were being treated for a combination of cervical and lumbar myofascial syndromes. The majority $(60 \%)$ of the patients in this sample did not have back surgery. All patients were on at least one type of medication. The non-narcotic pain madication was the most popular (100\%) followed by sleep medications ( $85 \%)$, narcotic (50\%) and antidepressants (35\%) .

\section{Analysis of the Response Variables}

Subjects' stated (self-reports) of activity levels obtained through the interview - were reported for the variables of sitting, standing, walking, kneeling, squatting, and stair climbing. Analyses of the results obtained are presented in Table 5. On the average, patients' 
stated tolerances were lower than those of the healthy subjects: 35 minutes of sitting and 22.3 minutes of standing as compared to 91 minutes and 39.6 minutes for the healthy subjects respectively; a walking tolerance of 7.5 blocks as compared to 23.4 blocks by the healthy subjects; 3.8 squats and 3.8 kneelings as compared to 17.4 squats and 18.9 kneelings for the healthy subjects; and finally 2.8 flights of stairs as compared to 10.2 flights for the healthy subjects. The table also presents the t-tests comparing groups for the respective variables. Results showed that the stated levels of performance were significantly lower for the patient group as compared to the healthy group ( $p<$ $0.001)$. This was true for all variables except for standing tolerance $(p<0.111)$.

Analysis of Squatting and Stair Climbing Variables

In order to address the objectives of this study, the stated (self-reported) and observed (measured) levels of performance in squatting and stair climbing were analyzed. Results presented in Table 6 are means, standard deviations, $t$ statistic, and $\mathrm{p}$ values upon comparing the patients and the healthy subjects. Mean squatting tolerances for the study groups are also presented in Figure 1.

Results for the squatting showed that the stated squatting tolerance (number of squats) was significantly 
lower for the patients' group as compared to the healthy group (mean of 3.8 and 17.4 respectively). The observed squatting tolerance was significantly lower for the patients' group as compared to the healthy group (mean of 8.1 and 21.0 respectively). The mean of the difference between stated and observed values is presented in Figure 3 . The time to perform squatting activity (Figure 4) was significantly higher for the patients' group as compared to the healthy group (mean of 4.8 and 3.5 squats per second respectively). In order to take into account the individual level of estimation of each subject, a new variable was introduced. This variable was calculated as: difference between what subjects estimated as being their performance level and what they had actually accomplished. The results of the t-tests conducted on the mean difference for each group separately indicated that, on the average, each group performed more squattings than what they stated $(p<0.001$ for each group). Further, results showed that there was no significant difference between the mean difference (observed-stated) for the two groups, $(p<.623)$. The patients' group, on the average, performed 4.3 more squats than they stated while the healthy performed only 3.6 more squats than stated.

The stated stair climbing tolerance (Figure 2) was significantly lower for the patients' group as compared to 
the healthy (mean of 2.8 and 10.2 respectively). The observed stair climbing ability was significantly lower for the patients' group as compared to the healthy (mean of 5.3 and 15.7 respectively). The time to perform stair climbing activity (Figure 4) was higher for the patients' group. However, the difference was not statistically significantly $(p<0.535)$. The results of the t-tests conducted on the mean difference for each group separately indicated that, on the average, subjects in each group climbed more flights of stairs than what they stated $(p<0.001)$. Further, results showed that there was no significant difference between the mean difference (observed-stated) for the two groups ( $p<$ 0.070). The patients' group, on the average, performed only 2.3 more flights of stairs than they stated while the healthy climbed 5.5 more flights than stated (Figure 3 ).

Results of the Analysis of Variance. The dependent variables described above were further examined using Analysis of Variance (ANOVA) procedures in order to account for the effect of gender in the study. ANovA results are presented in Table 7 for squatting. It can be seen that the findings of these analyses are similar to those reported in the previous section. That is, groups were significantly different on the basis of stated values and observed values, and time to perform squatting. A main effect of gender was noted for stated and observed tolerances. 
Interactions within groups were present for stated, observed, and time to perform. For all three variables, healthy male subjects performed at higher levels on the average than healthy female subjects and both male and female patients (Table 9 and Figure 5).

ANOVA results are presented in Table 8 for stair climbing. Once more, it can be seen that the findings of these analyses are similar to those reported in the previous section. That is, groups were significantly different on the basis of stated values and observed stair climbing values and were not different in the time to perform stair climbing. However, the difference between observed and stated tolerances between the two groups reached statistical significance once gender was accounted for $(p<0.038)$. A main effect of gender was noted for stated and observed tolerances. Interactions within groups were present for all four variables. Healthy male subjects performed at higher levels than healthy female subjects and both male and female patients in each case (Figure 6).

\section{Analysis of Pain Variables}

Results of analyzing the various pain variables obtained during patients' interviews as well as following testing are given in Table 10. Of interest in this table is that patients, on the average, reported significant increase 
in pain level following activities of squatting and stair climbing. In both of these cases, the change in pain level was statistically significant $(p<0.001)$. 


\section{Chapter V}

\section{Discussion and Implications}

Low back pain (LBP) is an ailment affecting the modern world. Whether people are young or older, working in an office or a factory, males or females, they are equally likely to be exposed to low back pain. Low back pain is not only a disease, it can result in disability that is costing the health care system billions of dollars each year. Low back pain is also a major source of psychosocial distress to its sufferers.

The management of low back pain has been baffling researchers and clinicians alike. Though not easy to attain, a desirable goal in LBP rehabilitation is pain reduction and functional restoration. Any approach to the management of the problem of LBP requires a method to evaluate its effectiveness. Great variations are found in the structure and method of evaluation of LBP. Clinicians tend to be interested in functional performance as well as self-report measures. Self-reported measures of function are reflections of the levels at which patients believe they are able to perform.

Low back pain affects all three subsystems of occupation. The performance system is affected because patients often are unable to perform activities of daily 
living due to pain. This in turn will affect habituation due to disruption or changes in roles and habits. Pain patients usually experience a decrease in self-esteem, lack of confidence in returning to work and fear of reinjury. These factors affect the volitional subsystem.

This study addressed a fundamental unanswered question in the literaure: how do patients rate their abilities in comparison to healthy subjects? Specifically, the objective of this study was to determine the relationship between patients' stated (or perceived) levels of function and their observed (or actual) levels of performance as compared to control subjects. Squatting and stair climbing were chosen because they are important components in many daily activities and tend to be limited in low back patients.

Findings of the study showed that there was a significant difference between what patients stated as their functional tolerances and what they actually accomplished (observed tolerances). This indicated that patients tend to underestimate their functional levels. The significant difference between stated and observed levels was also present for the healthy subjects. Healthy subjects also tended to underestimate what they can actually do. Collectively, whether subjects are patients with LBP or not, they seemed to underestimate their abilities of squatting and stair climbing. 
Additionally, patients' perceptions of functional levels and their performance were significantly lower than those of the healthy subjects. Patients required consistently more time to perform activities than healthy subjects. As was expected, these findings indicate that pain and injury to the back affect functional abilities negatively as reflected in the decline in what patients can do.

Findings of this study agree with previous reports (Linton\& Gotestam, 1983; Fordyce, 1984) in that all patients reported an increase in pain after the squatting and stair climbing.

When compared on the basis of the difference between stated and observed, to answer the research question, results showed that there was no significant difference between groups. This finding indicates that patients were, relatively as accurate in estimating their abilities as were the healthy subjects.

In general, healthy subjects performed at higher levels in both squatting and stair climbing as compared to the patients. They demonstrated ability to perform more squats, climb more flights of stairs, and perform all activities in less time than the patients. There is an almost unequivocal finding that chronic low back pain patients have rather low levels of activity compared to their pre-pain levels or to normal controls (Fordyce, 1981). 
Even though previous studies have signaled that culture affects patients' pain perception, in this study, no statistical difference was found in relation to ethnicity.

Therefore, for the sample and conditions of this study it can be concluded that underestimation of functional abilities is likely to take place in patients with low back pain as well as healthy subjects. Consequently, selfreported measures of functional ability should not be used in isolation and must be accompanied by actual measurement of the abilities.

\section{Recommendations}

The focus of this study was on the ability of patients with chronic low back pain to accurately predict their functional levels. The findings indicating that these patients did underestimate their abilities was consistent with the literature. However, at the same time, healthy subjects were also found to underestimate their functional levels. The fact that both healthy individuals as well as patients exhibited this behavior is an important finding that deserves further investigation. Due to the limitations of the size and nature of the sample included in this study, the results must be viewed as exploratory in nature. Futhur research is indicated. It is recommended that future reseach be conducted to study: 
1. Whether self-reported measures affect subsequent performance.

2. The relationship between self-report of activity level and actual performance, on one hand, and behavioral factors on the other hand.

3. Patterns of perceived abilities in activities of daily living other than squatting and stair climbing.

4. Task familiarity on estimation of abilities (e.g. for a group of individuals who frequently practice certain tasks such as lifting).

5. Whether other patient populations can accurately predict their performance.

\section{Summary}

The objective of this study was to determine the relationship between the stated (or perceived) and the observed (or actual) levels of squatting and stair climbing in a sample of 20 chronic low back pain patients as compared to control subjects. There was a significant difference between what subjects (patients and healthy) stated as their functional tolerances and what they actually accomplished (observed tolerances). This indicates that patients and healthy subjects underestimated their functional levels. Additionally, patients' perception of functional levels and their performance were significantly lower than those of the 
healthy subjects. Patients required consistently more time to perform activities than healthy subjects. When compared on the basis of the difference between stated and observed, to answer the research question, no significant difference between both groups was found. In other words, patients were as accurate in estimating their abilities as were the healthy subjects. Healthy subjects performed at higher levels in both squatting and stair climbing as compared to the patients. It was concluded that, for the sample and conditions of this study, underestimation of functional abilities is likely to take place in patients with low back pain as well as healthy subjects. Consequently, selfreported measures of functional ability should not be used in isolation and must be accompanied by actual measurement of the abilities. 


\section{References}

Bandura, A. (1977). Self-efficacy: Toward a unifying theory of behavioral change. Psyhcological Review, 84, 191215 .

Barnes, D. \& Benjamin, S. (1987). The self care assessment schedule (SCAS). Journal of Psychosomatic Research, 31, 191-202.

Becker, M. H., Haefner, D. P., Kasl, S. V., Kirsch, J. P., Maiman, L. A., \& Rosenstock, I. M. (1977). Selected psychosocial models and correlates of individual health related behaviors. Medical Care, 15, 27-46.

Blacklow, R.S. (1983). Signs and Symptoms: Applied Pathological Physiology and Clinical Interpretation, 6th edition. Philadelphia: J.B. Lippincott Co, pp. 770. Bonica, J. J. (1980). Pain research and therapy: Past and current status and future needs. In L. K. Young \& J. J. Bonica (Eds.), Pain, Discomfort and Humanitarian Care (pp. 1-46). Amsterdam: Elsevier.

Cairns, D., Thomas, L. Mooney, V. \& Pace, J. B. (1976). Comprehensive approaches to chronic low back pain. Pain, 2, 301-308.

Chapman, C.R., Casey, K.L. \& Dubner, R. (1985). Pain measurement: An overview. Pain, 22, 1-31. 
Council, J.R., Ahren, D.K., Follick, M.J. \& Kline, C.L. (1988). Expectancies and functional impairment in chronic low back pain. Pain, 33, 323-331.

Dolce, J.J., Crocker, M.F. \& Dolys, D.M. (1986). Prediction of outcome among chronic pain patients. Behavioral Research Therapy, 24, 313-319.

Eagle, R. (1979, october). A pain in the back. New Scientist, p. 170-172.

Follick, M. J. , Smith, T. W. \& Ahern, D. K. (1985). The sickness impact profile: a global measure in disability in chronic low back pain. Pain, 21, 67-76.

Fordyce, W. E. , Mc Mahon, R., Rainwater, G., Jackins, S., Questad, K., Murphy, T. \& Delateur, B. (1981). Pain complaint exercise performance relationship in chronic pain. Pain, 10, 311-321.

Fordyce, W. E. , Lansky, D., Calsyn, D. A., Shelton, J. L., Stolov, W.C. \& Rock, D.L. (1984). Pain measurement and pain behavior. Pain, 18, 53-69.

Funk \& Wagnalls standard Dictionary. (1984). Harper \& Row, Publishers, Inc. pp. 117, 653 .

Gamboa, A. M., Holland, G. H. , \& Tierney, J. P. (1988). Assessing work and earning capacity. Advances in Clinical Rehab, 2, 6-36. 
Granger, C.V. \& Greer, D.S. (1976). Functional status measurement and medical rehabilitation outcomes. Archives of Physical Medicine \& Rehabilitation, 57, 103-109.

Hasue, M. \& Fujiwara, M. (1979). Epidemic logic and clinical studies in long term prognosis of low back pain and sciatica. Spine, 4, 150-155.

Horal, J. (1969). The clinical appearance of low back disorders in the city of Gothenberg, Sweden. Acta orthopedic Scandinavia (Suppl.), 118, 171-176.

Hult, L. (1954). The Munkfors investigation. Acta Orthopedic Scandinavia, suppl. 16.

Jensen M.P., Karoly P., Braver S. (1986): Measurement of Clinical Pain Intensity: A Comparison of Six Methods. Pain, 27, 117-126.

Jensen, M.P., Turner, J.A., Romano, J.A. (1991). Selfefficacy and outcome expectancies: relationship to chronic pain coping strategies and adjustment. Pain, 44, 263-269.

Jette, A.M. (1980). Functional status index: reliability of a chronic disease evaluation instrument. Archives of Physical Medicine and Rehabilitation, 61, 395-401.

Katz, S., Downs, T.D., Cash, H.R. \& Grotz, R.C. (1970). Progress in development of index of ADL. Gerontologist, 10, $20-30$. 
Khalil, T.M., Goldberg, M.L., Asfour, S.S., Moty, E.A., Steele, R., Rosomoff, H.L. (1987). Acceptable maximum effort (AME): A psychophysical measure of strength in back pain patients. Spine, 12:4:372-376.

Kielhofner, G \& Burke, J. (1980). A model of human occupation, Part I: conceptual framework and content. American Journal of Occupational Therapy, 34, 9:572581.

Kielhofner, G. (Ed.). (1985). A Model of Human Occupation. Baltimore: Williams and Wilkins.

Kielhofner, G. (1992). Conceptual Foundations of Occupational Therapy. Philadelphia: F.A. Davis Co. Kirsch, I. (1986). Response expectancy and phobic anxiety. American Psychology, 41, 1391-1393.

Kores, R.C., Murphy, W.D., Rosenthal, T.L., Elias, D.B. \& North, W.C. (1990). Predicting outcome of chronic pain treatment via a modified self-efficacy scale. Behavior Research Therapy, 28, 2, 165-169.

Kremer, E. F., Block, A. J. \& Gaylor, M. S. (1981). Behavioral approaches to treatment of chronic pain: the inaccuracy of patient self-report measures. Archives Physical Medicine Rehabilitation, 62, 188-191.

Lankhorst, G.J., stadt, R.J. \& Vogelear, T.W. (1982). objectivity and repeatability of measurements in low back pain. Scandinavian Journal of Rehabilitation Medicine, 14, 21-26. 
Leavitt, S.S., Johnson, T.A. \& Bayer, R.D. (1971). The process of recovery patterns in industrial back injury: 1. Cost and other quantitative measures of effort. Industrial Medicine Surgery, 40, 7-14.

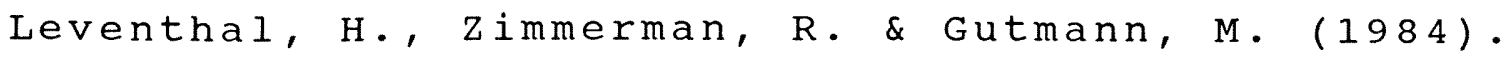
Compliance; a self-regulation perspective. In: W. D. Gentry (Ed.). Handbook of Behavioral Medicine. New York: Guilford Press.

Linton, S. J. \& Gotestam, K.G. (1983). A clinical comparison of two pain scales: correlation, remembering chronic pain, and a measure of compliance. Pain, 17, 57-65.

Locke, T.C. (1983, July). stretching away from back pain injury. Occupational Health and Safety, p. 8-14.

McGinnis, G.E., Seward, M.L., DeJong, G. \& Osberg, J.S. (1986). Program evaluation of physical medicine and rehabilitation department using self-report Barthel. Archives of Physical Medicine and Rehabilitation, 67, $123-125$

Nachemson, A. L., (1971). The lumbar spine: An orthopedic challenge. Spine, 1, 59-71.

ogden-Niemeyer, L. \& Jacobs, K. (1989). Tools for identification of abnormal illness behavior. In Work Hardening: State of the Art, (p. 92). New Jersey: Slack Inc. 
Price D.D., McGrath P.A., Rafii A. \& Buckingham B. (1983). The validity of visual analogue scales as ration scale measures for chronic and experimental pain. Pain, 17, 45-56.

Reilly, M. (1962). Occupational therapy can be one of the great ideas of the 20 th century. American Journal of occupational Therapy, 16, 1-9.

Richman, J., Makrides, L. \& Prince, B. (1980). Research methodology and applied statistics. Physiotherapy Canada, 32, 253-257.

Rintala, D.H. \& Willems, E.P. (1991). Telephone versus face-to-face mode for collecting self-reports of sequences of behavior. Archives of Physical Medicine and Rehabilitation, 72, 477-481.

Robinson, L. (1987). Patient compliance in occupational therapy home health programs: sociocultural considerations. Occupational Therapy in Health Care, 4 , $1, \quad 127-137$.

Roland, M. \& Morris, R. (1983). Development of reliable and sensitive measure of disability in low back pain. Spine, 8, 2, 663-672.

Rosenberg, M. L., (1980). Patients - The Experience of Illness. Philadelphia: Saunders Press. 
Rosenstiel, A. K. \& Keefe, F.J. (1983). The use of coping strategies in chronic low back pain patients: relationship to patient characteristics and current adjustment. Pain, 17, 33-44.

Rosomoff, H. L. (1985). The non-operative treatment of the failed back syndrome with chronic pain. In D.M. Long, (ed.) Current Therapy in Neurosurgery. Philadelphia, B. c. Decker.

Sanders, S.H. (1980). Toward instrument system for the automatic measurement of 'uptime' in chronic pain patients. Pain, 9, 103-109.

Sanders, S. H. (1983). Automated versus self-monitoring of "up-time in chronic low back pain patients: A comparative study. Pain, 15, 399-405.

Schaepe, J.L. (1982). Low Back Pain: An Occupational Perspective. In M. Stanton-Hicks \& R. Boas (Eds.) Chronic Low Back Pain (pp. 1-13). New York: Raven Press.

Schmidt, A.J. (1985). Cognitive factors in the performance level of chronic low back pain patients. Journal of Psychosomatic Research, 29, 183-189.

Schwartz, D. P. , De Good, D.E. \& Shutty, M.S. (1985). Direct assessment of beliefs and attitudes of chronic pain patients. Archives of Physical Medicine and Rehabilitation, 66, 806-809. 
Sheikh, K., Smith, D. S., Meade, T. W. , Goldenberg, E., Brennan, P. J., Kinsella, G., (1979). Repeatability and validity of a modified activities of daily living index in studies of chronic disability. International Rehabilitation Medicine, 1, 51-58.

Shutty, M. S. Jr., De Good, D. E. \& Schwartz, D. P. (1986). Psychological dimensions of distress in chronic pain patients: a factor analytic study of symptom checklist. Journal Consultation Clinical Psychology, 54, 836-842. Spiegel, J. S., Hirshfield, M. S., \& Spiegel, T. M., (1985) . Evaluating self-care activities: Comparison of a selfreported questionnaire with an occupational therapist interview. British Journal of Rheumatology, 24, 357361 .

SPSS/PC+ Guide (1991). Chicago: SPSS inc. Steinberg, G.G. (1982). Epidemiology of low back pain. In M. Stanton-Hicks \& R. Boas (Eds.) Chronic Low Back Pain (pp. 1-13). New York: Raven Press.

Turk, D. C. \& Holzman, A. D. (1988). Chronic pain; interfaces among physical, psychological, and social parameters. In: A.D. Holzman, D.C. Turk (Eds.) Pain Management: A Handbook of Psychological Treatment Approaches (p. 1-9). New York: Pergamon Press. 
United States Department of Labor, Employment and Training Administration (1981). Selected Charcateristics of Occupations Defined in the DOT. Washington, DC: US Government Printing office.

Webster's II New Riverside University Dictionary (1984). The Riverside Publishing Co.

White, J. \& Strong, J. (1992). Measurement of activity levels in patients with chronic pain. The Occupational Therapy Journal of Research, 12, 217-228.

Williams, D. A. \& Thorn, B. E. (1988). An empirical assessment of pain beliefs. Pain, 36, 351-358. 
Appendices 


\section{Purpose}

The purpose of this investigation is to record what you perceive as your functional levels and what you can actually do. You are one of twenty subjects expected to participate in the study.

\section{Procedures}

1. During this first session, you will be asked questions in order to gather basic information.

2. You will be asked to assess your ability to comfortably perform activities such as stair climbing, squatting, and a host of other activities.

3. Tomorrow, you will go through two performance evaluation session during which you will be asked to perform some of the activities just mentioned and your achievement will be scored.

\section{$\underline{\text { Risks }}$}

No risks are expected to be encountered. All subjects were instructed as to the study procedures and what was expected of them.

\section{Benefits}

No benefit are offered for your participation in this study.

\section{Confidentiality}

This investigator will consider your records confidential to the extent permitted by the law. Your files will be assigned a number and all reference will be through this designation. your records and results will not be identified in any publication without your expressed permission. 


\section{Right to Withdraw}

Your participation is voluntary and you have the right to withdraw from the study at any time without repercussion to you. Any question you have regarding this study will be answered gladly.

Signature of subject

Signature of Witness
Date

Date

Alma R. Abdel-Moty, OTR/L University of Miami

Comprehensive Pain \& Rehabilitation center 600 Alton Road, Miami Beach, Florida 33139. 
Appendix B

DATA FORM

INTAKE INTERVIEW

1. Name:

2. Date:

/ _ / 199

3. Group

1 Patients

2 Controls

4. Subject\# :

5. Patient \#:

6. Gender

$$
\begin{array}{ll}
1 & \text { Male } \\
2 & \text { Female }
\end{array}
$$

7. Contraindications

$\begin{array}{lll}1 & 2 & \text { knee replacement } \\ 1 & 2 & \text { hip replacement } \\ 1 & 2 & \text { uncontrolled hypertension } \\ 1 & 2 & \text { cognitive deficits } \\ 1 & 2 & \text { use of ambulation devices } \\ 1 & 2 & \text { other }\end{array}$

8. Weight: $1 \mathrm{~b}$

9. Height: __ inches

10. Obesity scale:

11. Ethnicity:

1 White non- Hispanic

2 Black non-hispanic

3 Asian

4 Native American

5 Hispanic white

6 Hispanic black

7 Other

12. How old are you? years 
13. What is your religion?

1 Catholic

2 Protestant

3 Jewish

4 Moslem

5 Baptist

6 None

7 other

14. What is your marital status?

1 Widowed

2 Married

3 Divorced

4 Separated

5 Never Married

15. How many years did you complete in school?

years

16. What are your educational credentials:

1 High school diploma

2 GED

$3 \quad \mathrm{AA}$

$4 \quad \mathrm{BA} / \mathrm{BS}$

$5 \quad$ MA $/$ MS

6 PHD

7 OTHER

17. [controls / patients] what is your present employment status?

1 Employed full time

2 Employed part time

3 Unemployed

$4 \quad$ Retired

5 Retired on Disability

6 Not employed and seeking work

7 Not employed and not seeking work

8 Full time student

9 Part time student

10 Full-time homemaker

18. [Controls] what is your present job?

[Patients] what was the last job you did prior to your present medical condition?

19. Physical Demands of the job [complete later]

1 Sedentary (up to 10 pounds)

2 Light (up to 20 pounds)

3 Medium (up to 50 pounds)

4 Heavy (up to 100 pounds)

5 Very heavy (more than 100 pounds) 
20. [Patients] Do you plan to return to your previous job?

1 Yes

2 No

3 I Do not know

4 I did not have a previous job

21. [Patients] How long has it been since you started experiencing your present pain?

$1 \quad$ less than 6 months

2 six months to a year

3 more than a year to five years

4 more than five years to ten years

5 more than ten years

22. How long can you presently sit in a chair until you must get up (because of pain)?

minutes

23. How long can you presently stand until you must move or sit (due to pain)?

-- minutes

24. How many blocks can you presently walk until you must stop (due to pain) if 10 blocks equal one mile?

-- blocks

25. How many times can you presently squat until you must stop (due to pain)?

times

26. How many times can you presently kneel on one knee holding onto support until you must stop (due to pain)? -- times

27. How many flights of stairs can you presently climb up and descend until you must stop (due to pain) if one flight is 10 steps?

-- flights 


\section{FOR THE PATIENT GROUP:}

28. Financial class

1 Workers Compensation

2 Private

3 Medicare

4 Liability

5 other

29. Admission status

1 Inpatient

2 Outpatient

30. Primary Diagnosis

1 lumbar myofascial syndrome

2 Cervical and lumbar myofascial syndrome

3 lumbar radiculopathy

4 spondylosthesis

5 herniated disc

6 neuropathy

7 arthritis lumbar spine

8 Other

31. Medical History

12 diabetes

12 hypertension

12 back surgery

12 other

32. Medications $(1=$ Yes, $2=$ No)

12 Non-Narcotic (example: Aspirin, Tylenol)

12 Narcotic (example: Percodan, Percocet)

12 Antidepressants (example: Elavil, Triavil, Tofranil, Sinequan)

12 Tranquilizers (example: Valium, Librium, Ativan, Xanax, Barbiturates)

12 Major Tranquilizers (example: Haldol, Prolixin, Trialfon)

12 Sleep Medications (example: Restoril, Dalmane, Halcyon)

33. Precautions

\begin{tabular}{lll}
1 & 2 & controlled high blood pressure \\
1 & 2 & asthma \\
1 & 2 & pacemaker \\
1 & 2 & other \\
\hline
\end{tabular}




$$
\text { Appendix C }
$$

Performance Data

NAME :

SUB. \#

ACTIVITY: $\quad$ Squatting

PRETEST:

Pain

Location

Reps

POSTTEST:

Pain

Location

Reps

Time

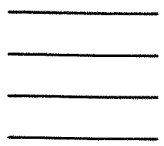

ACTIVITY: Stair climbing

PRETEST:

Pain

Location

Reps

POSTTEST:

Pain

Location

Reps

Time

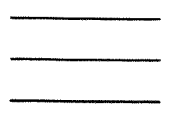

COMMENTS :

MEDICATIONS : 
Appendix D

Visual Analog Scale (VAS) 
Name:

1. Rate your average pain over the last 24 hours by placing a line on the scale below.

$\begin{array}{ll}\hat{\text { No }} & \hat{A} \\ \text { Pain } & \text { Pain as bad } \\ & \text { as it could be }\end{array}$

2. Let us know what level of pain you consider intolerable by placing a line on the scale below.

$\begin{array}{ll}\text { No } & \hat{A} \\ \text { Pain } & \text { Pain as bad } \\ & \text { as it could be }\end{array}$

3. Let us know for what level of pain you would take medications by placing a line on the scale below.

$\begin{array}{ll}\hat{\text { No }} & \hat{\text { Pain as bad }} \\ \text { Pain } & \text { as it could be }\end{array}$

4. Let us know which level of pain you consider disabling by placing a line on the scale below.

$\begin{array}{ll}\text { No } & \wedge \\ \text { Pain } & \text { Pain as bad } \\ & \text { as it could be }\end{array}$

5. Let us know how your pain has changed over the last month by placing a line on the scale below.

$\begin{array}{ll}\text { No } & \hat{A} \\ \text { Pain } & \text { Pain as bad } \\ & \text { as it could be }\end{array}$


Appendix E

Tables 
Table 1

Demographic Variables of Both Study Groups

\section{Sample size}

Gender

Male

Female

Ethnicity

White non- Hispanic

Black non-hispanic

Asian

Hispanic white

Hispanic black
Patients

Freq \%

$20 \quad 100$

10

10

12

3

1

4
0

50

50

10

10

Healthy

Freq \%

\section{Religion}

Catholic
Protestant
Jewish
Moslem
Baptist
None
Other

Marital status
Married
Divorced

Never Married

$\begin{array}{lr}8 & 40 \\ 1 & 5 \\ 4 & 20 \\ 0 & 0 \\ 1 & 5 \\ 6 & 30 \\ 0 & 0\end{array}$

$\begin{array}{rr}13 & 65 \\ 0 & 0 \\ 1 & 5 \\ 1 & 5 \\ 0 & 0 \\ 2 & 10 \\ 3 & 15\end{array}$

$\begin{array}{rr}12 & 60 \\ 2 & 10 \\ 6 & 30\end{array}$

$\begin{array}{rr}11 & 55 \\ 4 & 20 \\ 5 & 25\end{array}$

Education

High school diploma GED

$\mathrm{AA}$

$\mathrm{BA} / \mathrm{BS}$

$\mathrm{MA} / \mathrm{MS}$

PHD

Other

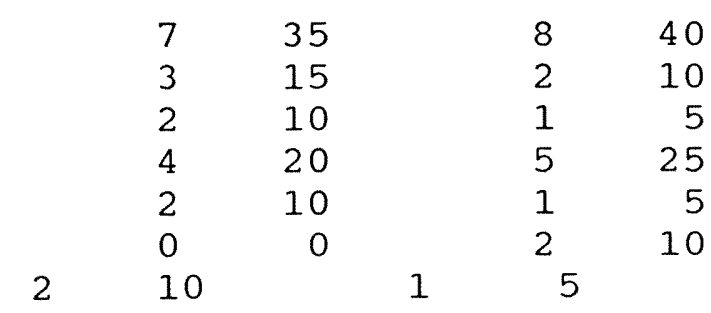

Employment status

Employed full time

Employed part time

Unemployed

Retired

Not employed \&

seeking work

$\begin{array}{rrrr}10 & 50 & 19 & 95 \\ 2 & 10 & 1 & 5 \\ 2 & 10 & 0 & 0 \\ 1 & 5 & 0 & 0 \\ 5 & 25 & 0 & 0\end{array}$


Table 2

Chi-square Comparison Between Groups on Categorical Demographic Variables

Variable
Patient Healthy ChiFreq $\%$ Freq $\%$ square
Ethnicity

White Non-Hispanic White Hispanic Other

Employment status

Employed Full Time Not Employed Full Time
10

10
12

$4 \quad 20 \quad 11$

4203

5.41

0.067

30

55

15
8.03
$0.005 *$

* statistically significant at $p<0.05$. 
Table 3

Means and standard Deviations of Quantitative Demographic Variables of study Groups.

Patient

Age, years

Height, inches

Weight, $1 \mathrm{~b}$

Obesity Index

Years in school

Job Category*
42.7
$(12 \cdot 3)$

66.8

(3.7)

$$
167.8
$$

(33.5)

6.6

(11.6)

14.3

(3.9)

2.6

(0.9)
Healthy

$t$

$\mathrm{p}$
41.8

(12.3)

66.3

(3.6)

158.6

(32.7)

3.6

$(10.6)$

15.0

$(3.8)$

2.5

$(0.8)$
0.22

0.828

0.39

0.701

0.88

0.393

0.86

0.385

0.593

$-0.54$

0.36

0.723

* Job categories range from 1 (sedentary) to 5 (very heavy) type jobs; according to the Dictionary of Occupational Titles (DOT, 1981).

** $\quad p<0.05$ indicates a statistically significant difference between groups. 
Table 4

Descriptive Information of the Patient study Group.

Pain Duration

$<6$ months

6 months - 1 year

1 year - 5 years

15

5 years - 10 years

45

$>10$ years

15

$\begin{array}{lr}3 & 15 \\ 1 & 5\end{array}$

Plan to Return to Previous Job

Yes

I do not know

I did not have a previous job

15

Financial class

Workers compensation

Private

$\begin{array}{rl}14 & 70 \\ 4 & 20 \\ 2 & 10\end{array}$

Medicare

Admission status

Inpatient

outpatient

Primary Diagnosis

Lumbar myofascial syndrome $\quad 16 \quad 80$

Cervical \& lumbar myofascial syndrome $4 \quad 4 \quad 20$

Back surgery

Yes

20

No

16

80

Medications

Non-Narcotic

Narcotic

Antidepressants

Tranquilizers

sleep Medications

17

85

Precautions

Controlled High Blood Pressure Asthma

None

$\begin{array}{rr}1 & 5 \\ 1 & 5 \\ 18 & 90\end{array}$




\section{Table 5}

Means and standard Deviations of stated Tolerances obtained During Initial Interview of the study Groups.

Patient Healthy $t \quad p$

\section{stated Tolerances}

sitting, mins

$\begin{array}{cc}35.0 & 91.0 \\ (19.5) & (54.4)\end{array}$

Standing, mins

$\begin{array}{cc}22.3 & 39.6 \\ (26.7) & (39.2)\end{array}$

Walking, blocks

7.5

(6.4)

23.4

(14.5)

squatting, reps

3.8

(3.4)

17.4

(8.0)

Kneeling, reps

3.8

(3.4)

18.9

(9.4)

4.33

$0.001 *$

stair climbing, flts

$\begin{array}{ll}2.8 & 10.2 \\ (2.5) & (6.4)\end{array}$

1.64

0.111

4.51

$0.001 *$

(1)
(2.5)

$\mathrm{p}<0.05$ indicates statistically significant difference between groups. 
Table 6

Means and standard Deviations of the squatting and stair climbing Response Variables of the study Groups.

Patient Healthy

$t$

$\mathrm{p}$

squatting:

mean mean

(SD)

(SD)

Stated Tolerance, reps

3.8

(3.4)

17.4

(8.0)

Observed Tolerance, reps

8.1

$(2.0)$

21.0

(8.0)

(Observed-stated), reps

4.3

(2.9)

3.6

(5.6)

Time to Perform, sec/reps

4.8

(1.1)

3.5

(1.5)

6.99

$0.001 *$

7.01

$0.001 *$

0.50

0.623

$(1.1) \quad(1.5)$

\section{stair climbing:}

Stated Tolerance, reps

$\begin{array}{ll}2.8 & 10.2 \\ (2.5) & (6.4)\end{array}$

4.76

$0.001 *$

Observed Tolerance, reps

5.3

(3.4)

15.7

$(10.4)$

(Observed-stated), reps

2.3

(2.8)

5.5

(6.9)

Time to Perform, sec/reps

14.2

(3.9)

13.4

(4.3)

4.26

$0.001 *$

3.06

$0.004 *$

0.63

0.535

* $\mathrm{p}<0.05$ indicates a statistically significant difference between groups. 
Table 7

Summary of the Analysis of Variables (ANOVA) Results for the squatting variable

Sum of Mean

Source of Variation Squares DF Square

GROUP:

Stated Tolerance

Observed Tolerance

(Observed - stated)

Time to Perform

GENDER :

Stated Tolerance

Observed Tolerance

(Observed - Stated)

Time to Perform

1836.0
1651.2
4.9
15.9

1

1836.0

1651.2

4.9

15.9

69.06

69.48

0.24

11.44

$.001 *$

$.001 *$

.629

$.002 *$

$\begin{array}{rr}225.6 & 1 \\ 265.2 & 1 \\ 1.6 & 1 \\ 4.4 & 1\end{array}$

225.6

8.48

265.2

1.6

11.16

0.08

$.006 *$

4.4

3.16

.782

.084

GROUP X GENDER:

stated Tolerance

Observed Tolerance

(Observed - stated)

Time to Perform

\footnotetext{
* $\quad p<0.05$ indicates a statistically significant difference between groups.
}

$\begin{array}{rrrrr}245.0 & 1 & 245.0 & 9.22 & .004 * \\ 156.0 & 1 & 156.0 & 6.60 & .015 * \\ 10.0 & 1 & 10.0 & 0.48 & .491 \\ 10.0 & 1 & 10.0 & 7.18 & .011 *\end{array}$


Table 8

Summary of the Analysis of variables (ANOVA) Results for the stair climbing variable

sum of

Source of Variation
Squares

\section{Mean}

Square
F

$\mathrm{p}$

\section{GROUP:}

Stated Tolerance

observed Tolerance

(Observed - stated)

Time to Perform

525.6
1081.6
99.2
6.6

1
1
1
1
525.6
1081.6
99.2
6.6
28.68
30.75
4.63
0.46
$.000 *$
$.000 *$
$.038 *$
.504

\section{GENDER:}

Stated Tolerance

$\begin{array}{rr}133.2 & 1 \\ 577.6 & 1 \\ 156.0 & 1 \\ 8.7 & 1\end{array}$

133.2

577.6

156.0

8.7
7.27
16.42
7.28
0.60
$.011 *$
$.000 *$
$.011 *$
.444

(Observed - stated)

Time to Perform

1

\section{GROUP X GENDER}

Stated Tolerance

observed Tolerance

$\begin{array}{rrr}87.0 & 1 & 87.0 \\ 422.5 & 1 & 422.5 \\ 126.0 & 1 & 126.0 \\ 108.5 & 1 & 108.5\end{array}$
4.75
12.01
5.88
7.49

$.036 *$
$.001 *$
$.020 *$
$.010 *$

Time to Perform

$p<0.05$ indicates groups. 
Table 9

Mean Values of Squatting and stair climbing Tolerances for Males and Females in Both study Groups.

Variable

\section{Patients}

Males

Females

3.7

3.9

8.7

7.5

5.0

3.6

5.0

$4 \cdot 6$

2.7

$4 \cdot 4$

Time to Perform

(sec/squat)

Stair Climbing:

Stated Tolerance

Observed Tolerance

(Observed-stated)

Time to Perform (sec/flight)
$3 \cdot 3$

2.6

13.5

6.9

5.8

4.7

22.7

8.6

2.5

2.1

9.2

1.7
13.0

11.2

15.5 
Table 10

Means and standard Deviations Pain Variables.

Variable
Mean
Standard

Deviation $t$

$\mathrm{p}$

Average Pain over

Last 24 hourst

62.3

21.5

Level of Pain

Considered Intolerable 77.0

18.0

Level of Pain to

Take Medication

77.0

13.9

Level of Pain

Considered Disabling

81.5

12.2

Change of Pain

over Last Month

72.2

20.2

\section{Pain Level:}

Pre squatting

Post squatting

Change (Post-Pre)

57.2

13.2

61.7

14.3

4.5

5.3

3.79

$0.001 *$

Pre stair climbing Post stair climbing Change (Post-Pre)

56.2

64.1

7.9
14.2

14.2

5.9

6.01

$0.001 *$

* $\quad p<0.05$ indicates a statistically significant difference between groups.

$+\quad$ Note: pain level is reported in millimeters on the visual scale of 0 to 10 centimeters. 
Appendix F

Figures 


\section{Fig. 1. Stated \& Observed Squatting Tolerances for the Study Groups}

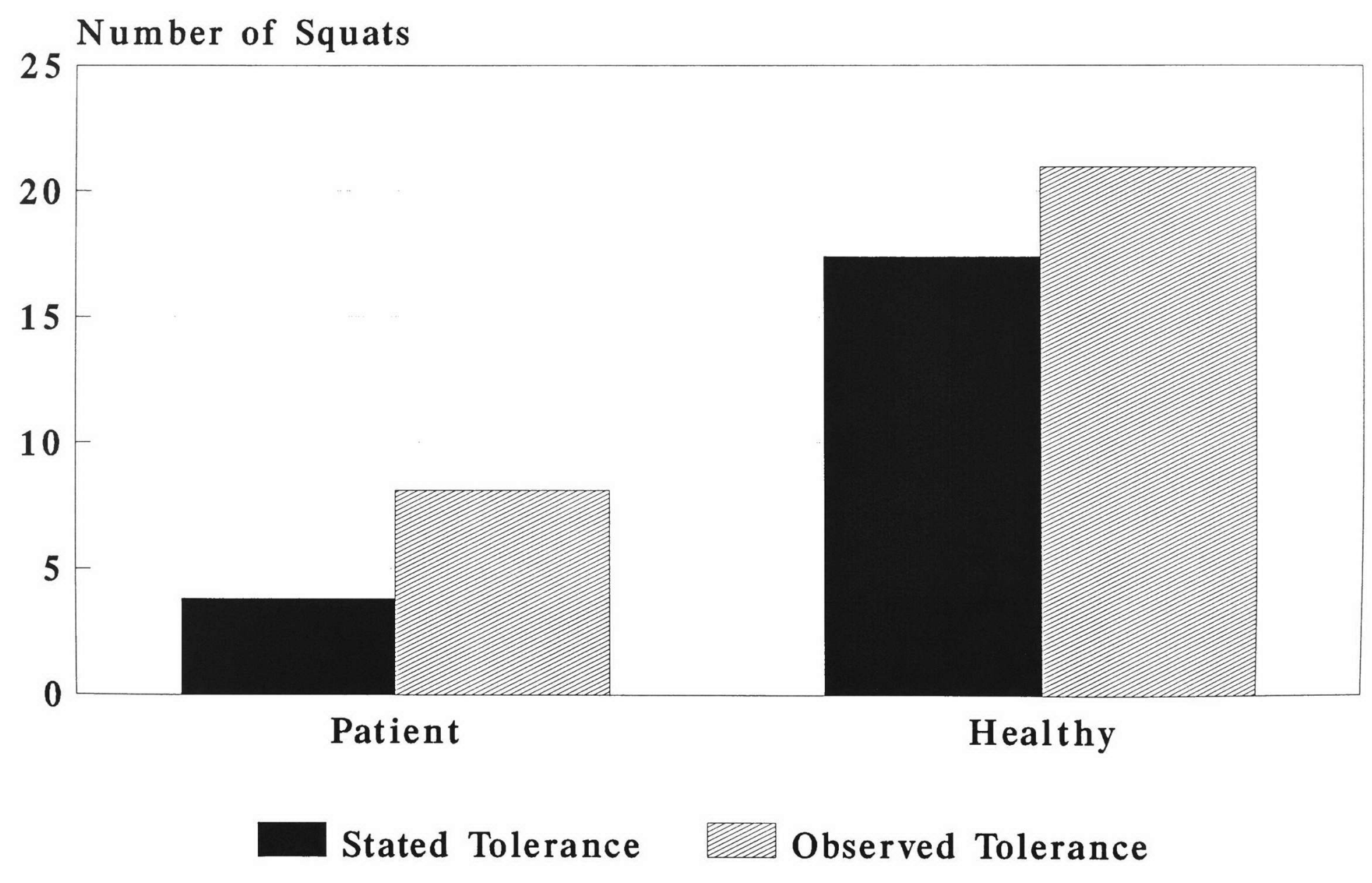




\section{Fig. 2. Stated \& Observed Stair Climbing Tolerance for the Study Groups}

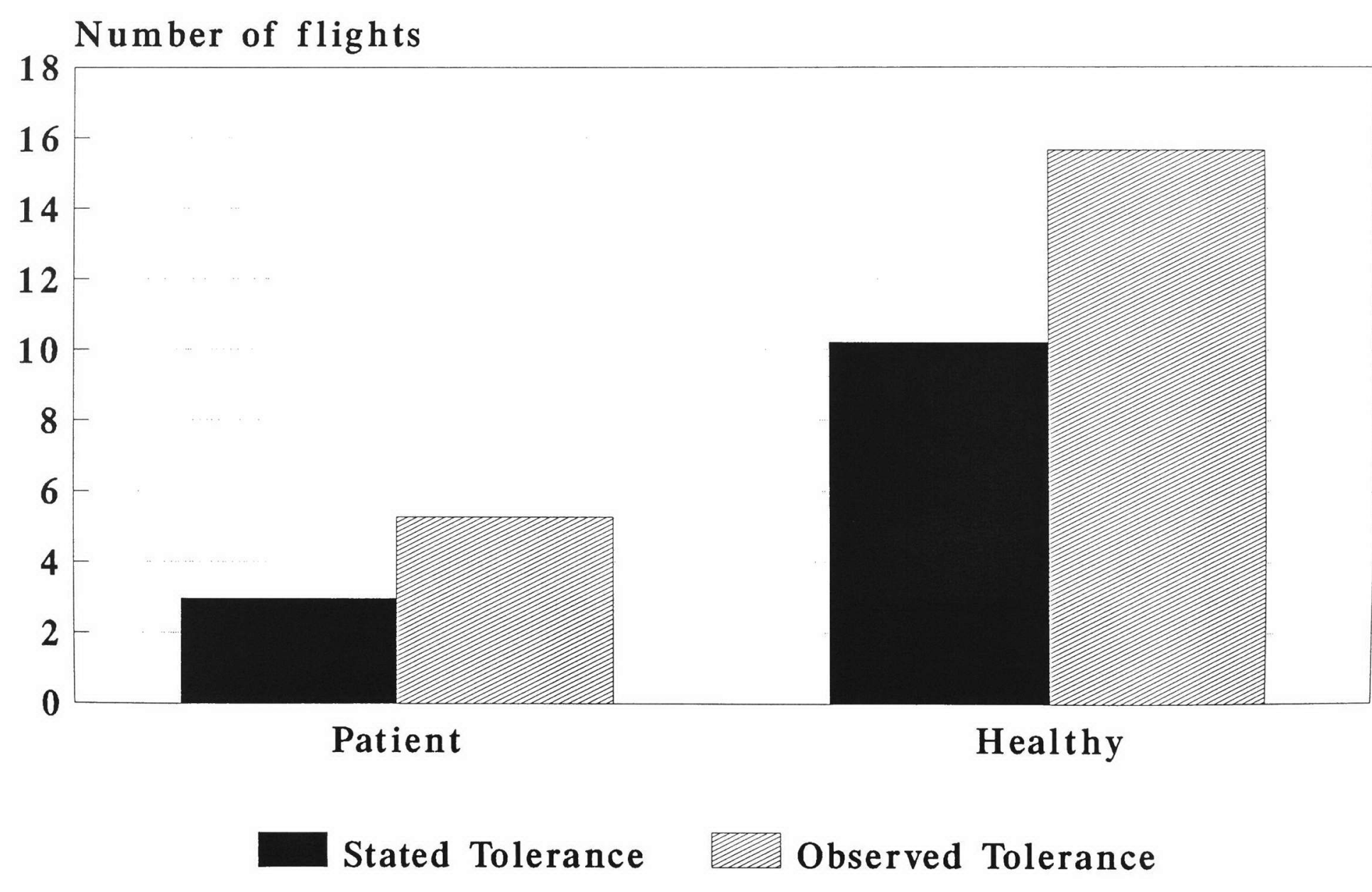




\section{Fig. 3. (Observed - Stated) Squatting \& Stair Climbing for the Study Groups}

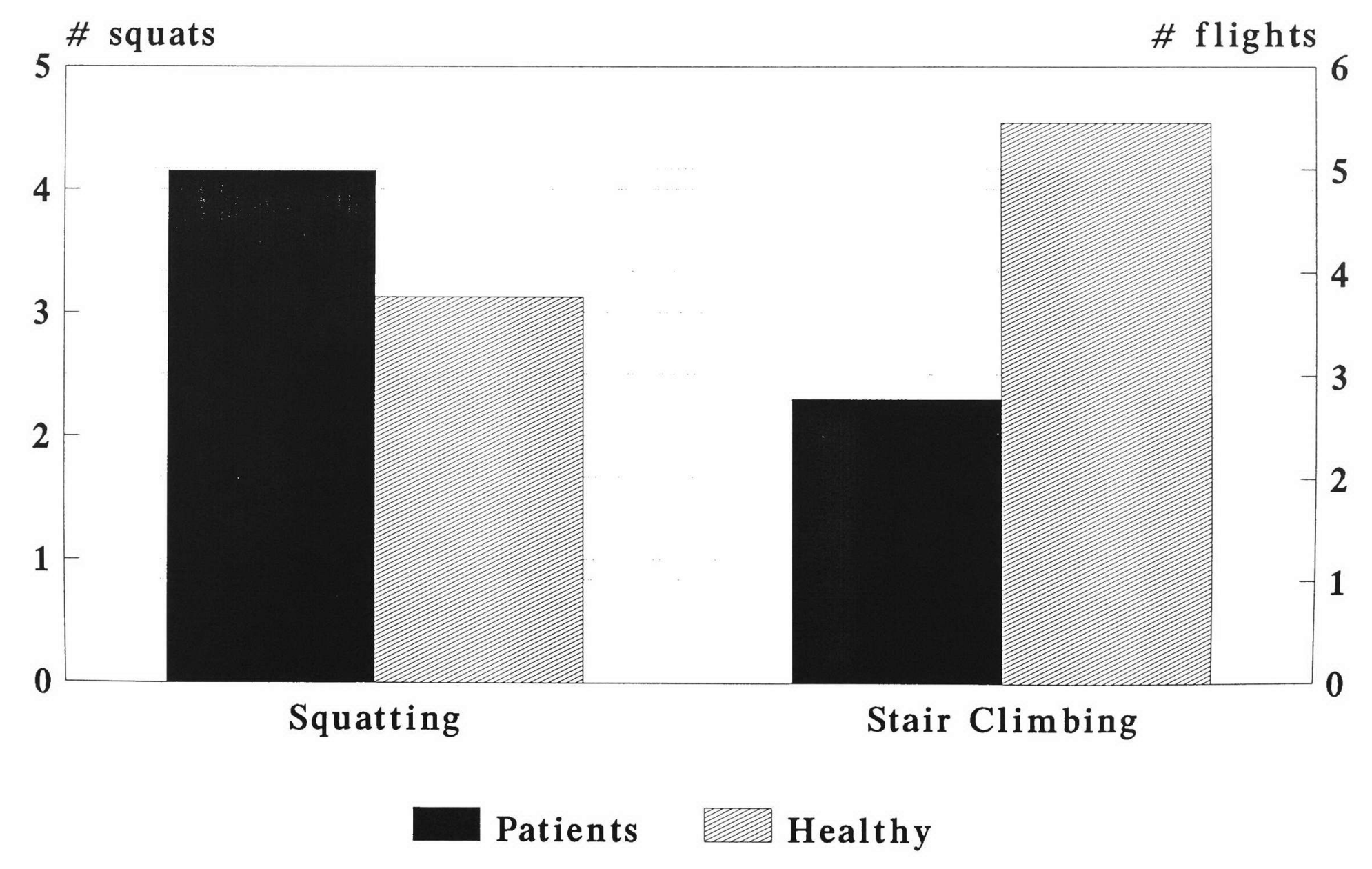


Fig. 4. Time to Perform Squatting \& Stair Climbing for the Study Groups

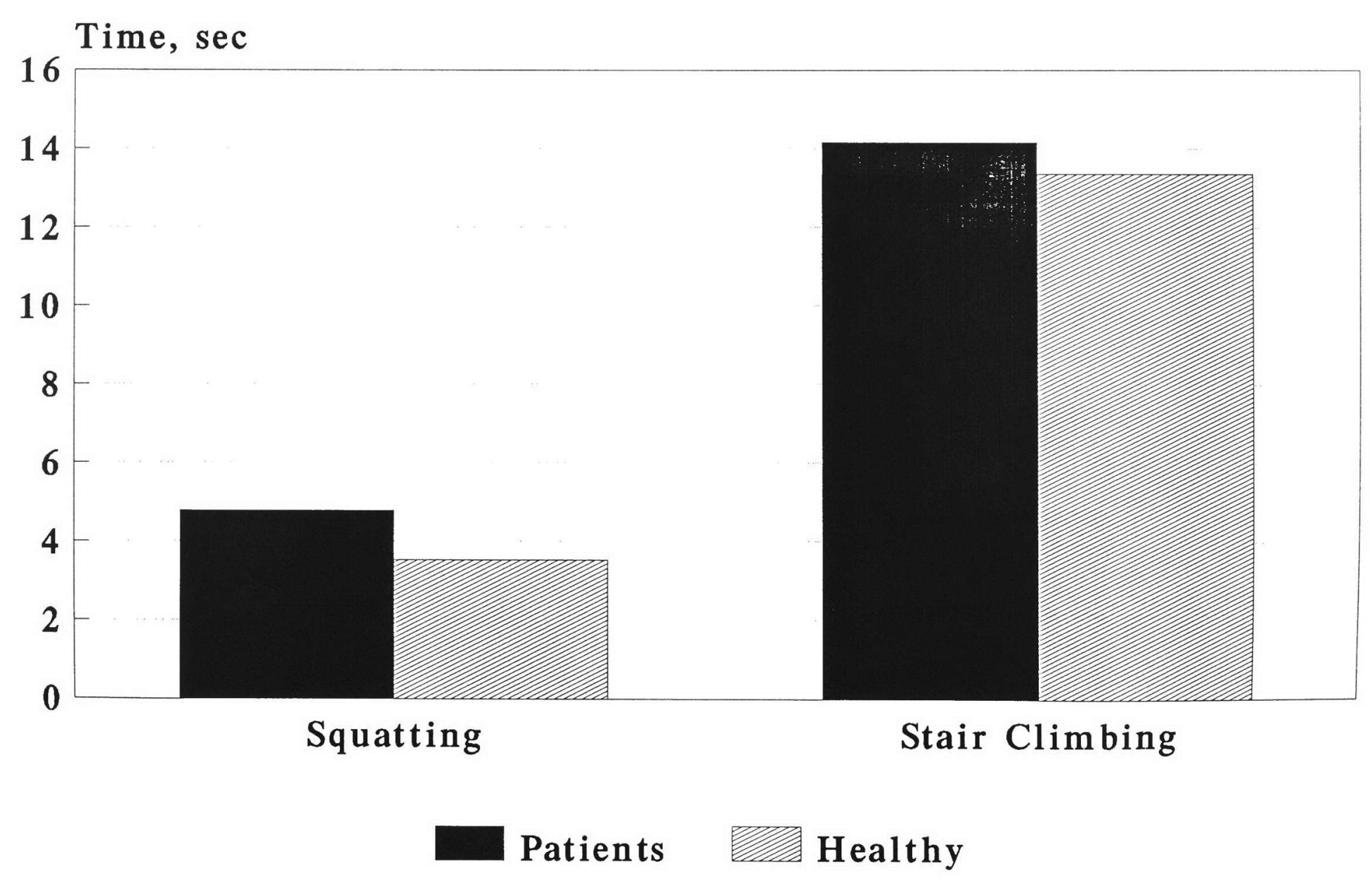


Fig. 5. Stated and Observed Squatting Tolerance for the Study Groups by Gender

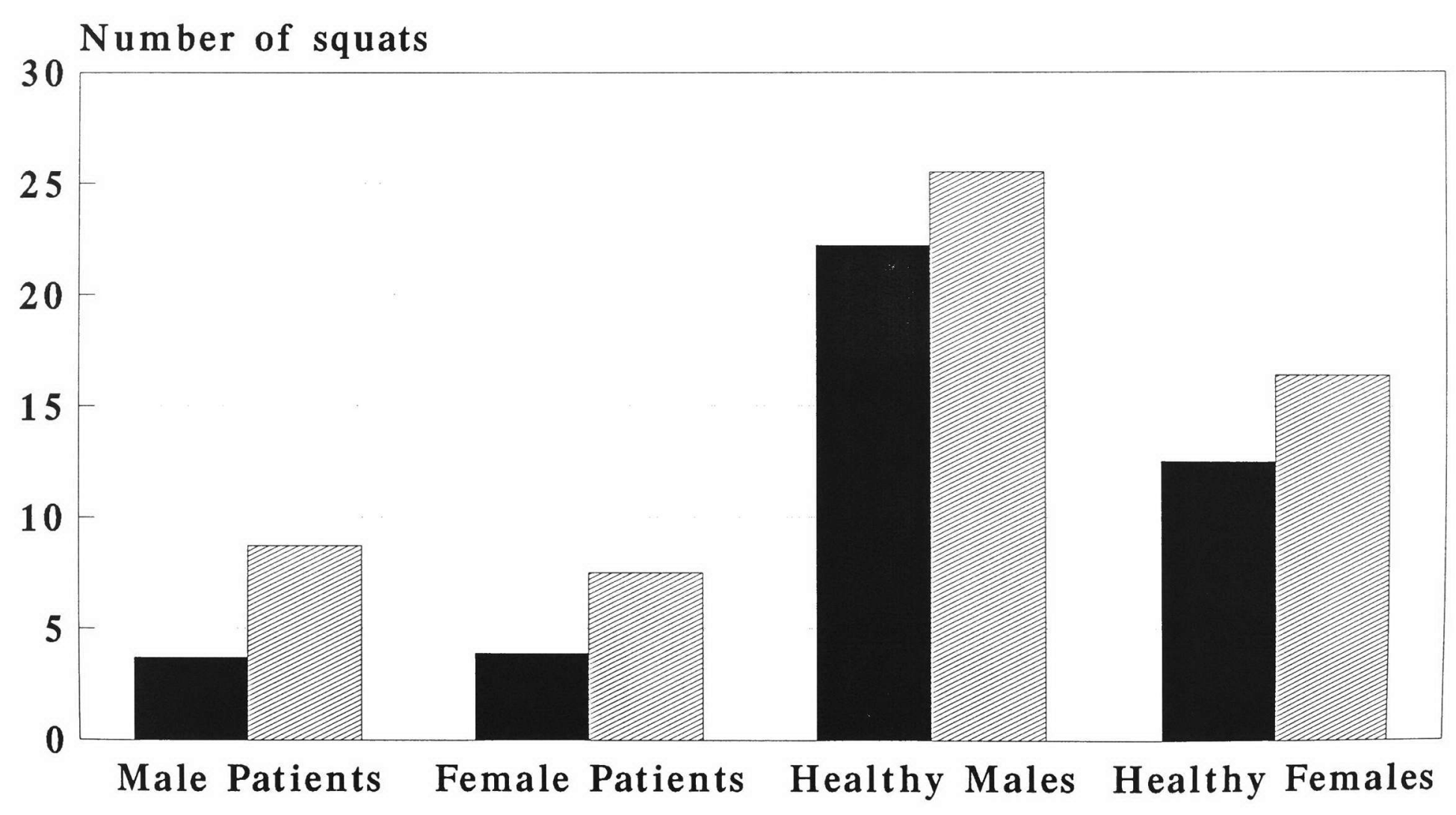

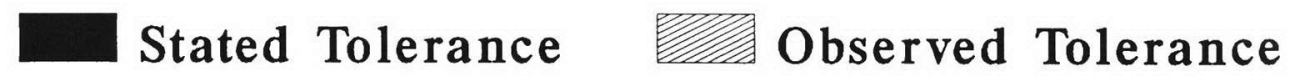




\section{Fig. 6. Stated and Observed Stair Climbing for the Study Groups by Gender}

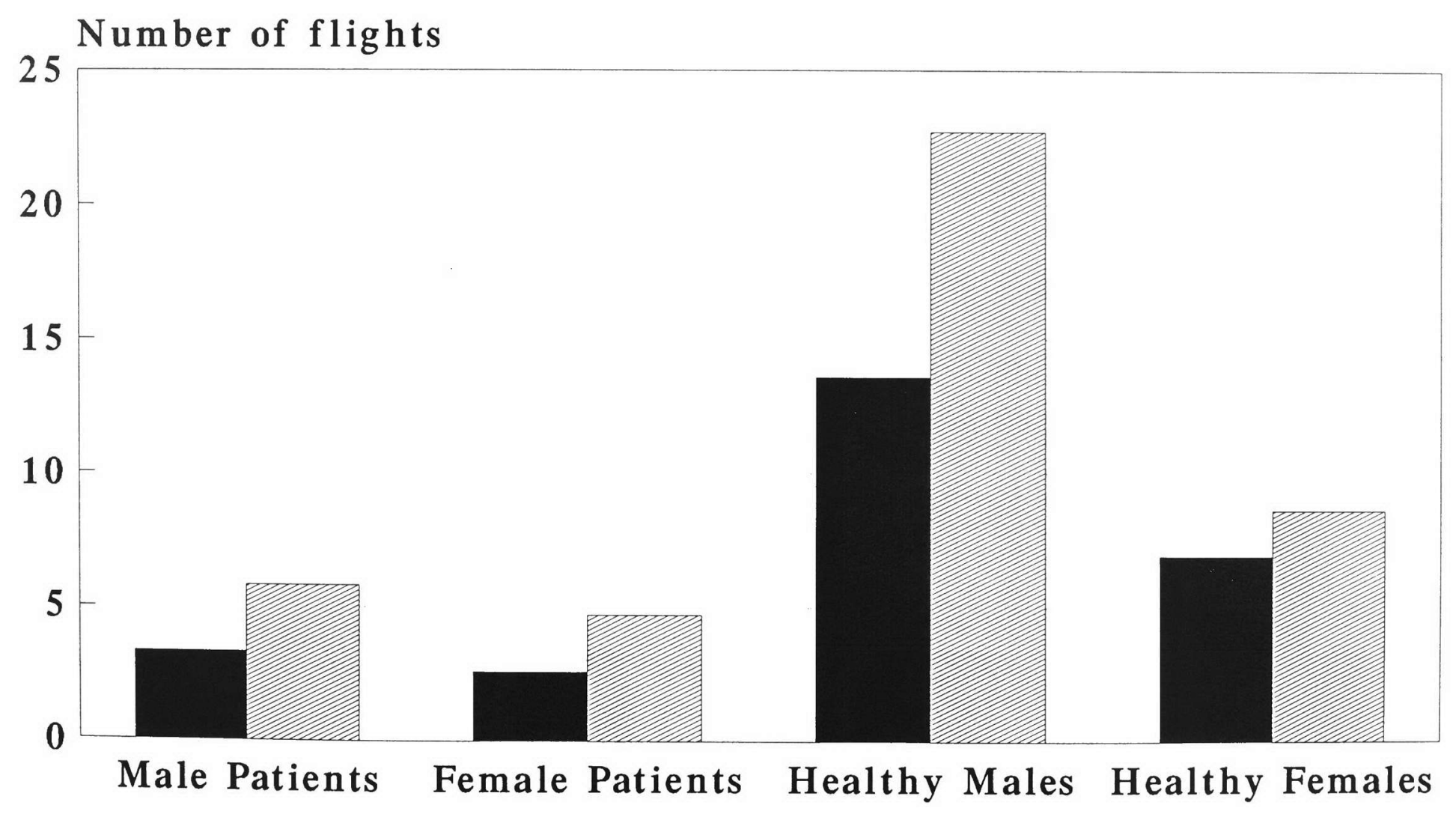

